\title{
Dispersion of tsunamis: does it really matter?
}

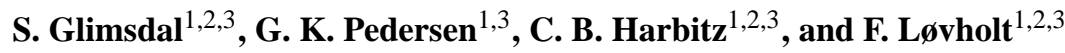 \\ ${ }^{1}$ International Centre for Geohazards (ICG), Sognsveien 72, Oslo, Norway \\ ${ }^{2}$ Norwegian Geotechnical Institute, Sognsveien 72, Oslo, Norway \\ ${ }^{3}$ University of Oslo, Blindern, Oslo, Norway \\ Correspondence to: S. Glimsdal (sgl@ ngi.no)
}

Received: 30 November 2012 - Published in Nat. Hazards Earth Syst. Sci. Discuss.: Revised: 5 April 2013 - Accepted: 24 April 2013 - Published: 18 June 2013

\begin{abstract}
This article focuses on the effect of dispersion in the field of tsunami modeling. Frequency dispersion in the linear long-wave limit is first briefly discussed from a theoretical point of view. A single parameter, denoted as "dispersion time", for the integrated effect of frequency dispersion is identified. This parameter depends on the wavelength, the water depth during propagation, and the propagation distance or time. Also the role of long-time asymptotes is discussed in this context. The wave generation by the two main tsunami sources, namely earthquakes and landslides, are briefly discussed with formulas for the surface response to the bottom sources. Dispersive effects are then exemplified through a semi-idealized study of a moderatestrength inverse thrust fault. Emphasis is put on the directivity, the role of the "dispersion time", the significance of the Boussinesq model employed (dispersive effect), and the effects of the transfer from bottom sources to initial surface elevation. Finally, the experience from a series of case studies, including earthquake- and landslide-generated tsunamis, is presented. The examples are taken from both historical (e.g. the 2011 Japan tsunami and the 2004 Indian Ocean tsunami) and potential tsunamis (e.g. the tsunami after the potential La Palma volcanic flank collapse). Attention is mainly given to the role of dispersion during propagation in the deep ocean and the way the accumulation of this effect relates to the "dispersion time". It turns out that this parameter is useful as a first indication as to when frequency dispersion is important, even though ambiguity with respect to the definition of the wavelength may be a problem for complex cases. Tsunamis from most landslides and moderate earthquakes tend to display dispersive behavior, at least in some directions. On the other hand, for the mega events of the last decade dispersion during deep water propagation is mostly noticeable for transoceanic propagation.
\end{abstract}

\section{Introduction}

Most tsunami modelers rely on the shallow-water equations for predictions of propagation and run-up. Some groups, on the other hand, insist on applying dispersive wave models, sometimes even with enhanced nonlinear properties. These models are in-house models or available as standard codes, free or commercial. Some of these are fairly well suited for implementation of tsunami applications. In the examples presented herein we employ an in-house model (Pedersen and Løvholt, 2008; Løvholt et al., 2008, 2010) which is designed for long-distance propagation of dispersive tsunamis. Using this model, we may take the Japan 2011 tsunami across the Pacific Ocean on a standard desktop during some hours of CPU time. The standard models, such as COULWAVE (Lynett et al., 2002; Kim and Lynett, 2011) and FUNWAVE (Kennedy et al., 2000; Shi et al., 2012) are based on moredemanding numerical schemes and incorporate a number of effects that are not relevant for oceanic propagation. Hence, simulations of oceanic propagation on single CPUs using these models may therefore be too time consuming. However, parallel features (e.g. Sitanggang and Lynett, 2005; Pophet et al., 2011; Shi et al., 2012) of the models should enable large-scale applications.

While the employment of dispersive codes for tsunami computation certainly boosts the CPU times and memory requirements, the significance of the extra physical features such codes inherit are met with skepticism by many tsunami modelers, at least for seismic tsunamis. On the other hand, a proper description of the wave generation by landslide tsunamis, and subaerial landslides in particular, requires primitive wave models, as demonstrated for the potential $\mathrm{La}$ Palma tsunami (Gisler et al., 2006; Abadie et al., 2012) and the 1998 Papua New Guinea tsunami (Grilli and Watts, 2005; 
Tappin et al., 2008). For such cases the waves are also dispersive in the far-field. Long-term propagation of dispersive waves may be approximated by ray (optical) methods (Ward, 2001; Ward and Day, 2001). If the waves are moderately dispersive, Boussinesq models without the optical approximation are now capable of simulating the far-field tsunami propagation over transoceanic distances (see e.g. Løvholt et al., 2008; Zhou et al., 2011; Kirby et al., 2013).

The variation of landslide thickness, relative to the water depth, may contribute to dispersion (Ward, 2001). However, the hydrodynamic response from the uplift filters short-scale variations due to landslide volume displacements (Geist, 1998b; Glimsdal et al., 2011; Kajiura, 1963; Løvholt et al., 2012b; Pedersen, 2001). Generally, the leading-order wave is reduced due to dispersion. In the far-field, however, the trailing wave system is expected to eventually dominate (Løvholt et al., 2008). Finally, frequency dispersion is of less importance for waves generated by large and sub-critical submarine landslides with moderate acceleration and deceleration where large wavelength components dominate (Harbitz et al., 2006). In these cases the Froude number $\ll 1$. (Froude number is the ratio between the landslide velocity and the local wave speed.) This is true for e.g. the Storegga tsunami (Harbitz, 1992b; Bondevik et al., 2005).

Although frequency dispersion is often considered negligible for earthquake-induced tsunamis, it may become noticeable and sometimes important. Løvholt et al. (2012b) showed that the seabed displacement due to heterogeneous coseismic slip gave rise to frequency dispersion, affecting the tsunami run-up. The propagation of the 2004 Indian Ocean tsunami gave noticeable dispersion in the Bengal Bay and Andaman Sea (Ioualalen et al., 2007; Horrillo et al., 2006), becoming more distinct at transoceanic distances (Glimsdal et al., 2006). Similarly, frequency dispersion for the long-distance propagation of the 2011 Tohoku tsunami is clear (Løvholt et al., 2012b; Grilli et al., 2012). For smaller earthquakes involving shorter-length scales, dispersion is expected to be pronounced at shorter-wave propagation distances. This is for instance demonstrated for the 2009 Samoa tsunami by Zhou et al. (2012).

Frequency dispersion in combination with nonlinearity may cause the formation of undular bores during shoaling. Undular bores related to the 2004 Indian Ocean tsunami and the 1998 Papua New Guinea tsunami are discussed by Glimsdal et al. (2006) and Grue et al. (2008), and by Tappin et al. (2008), respectively. Recent investigations of the shoaling from potential ocean-wide tsunamis from La Palma also address this problem (Løvholt et al., 2008; Zhou et al., 2011).

In this paper we draw on the experience from a series of earthquake and landslide tsunamis to address the significance of dispersion. To this end we need control on crucial parameters in the computations and availability of sufficient data. Hence, the investigation is based primarily on cases where the authors have first-hand knowledge and full access to computational data. However, other studies from the literature are also included when feasible. The main focus is on dispersive effects during oceanic propagation in a linear context, even though nonlinearity may be present also in the generation and propagation for landslide tsunamis. Dispersion may also be important for constructive interference due to geometry and bore formation during shoaling. Generally, we do not address these phenomena. The exception is a brief example on the evolution of an undular bore, which occurs in one of the case studies that is presented. We start with a basic treatise on the effects of weak dispersion and identify a parameter that describes its significance. After discussing earthquake and landslide sources we demonstrate dispersion effects for a semi-idealized tsunami. Then, we move on to a series of case studies, including the mega tsunamis of the last decade, with an eye on the significance of the dispersion.

\section{Dispersion effects}

We distinguish between the dispersive effect acting during deep water propagation and the first part of the shoaling, when the earthquake tsunamis are linear, and the dispersion effects that may appear in shallow water, which are linked to nonlinearity and produce undular bores. The first type, which is the main concern in the present treatise, is described in Sect. 2.1, while the latter is presented in Sect. 2.2, somewhat more briefly.

\subsection{Linear dispersion during propagation}

Frequency dispersion is the spreading of energy in the direction of wave advance due to different wave celerity for wave modes of different length. For plane linear gravity waves propagating in an inviscid fluid of uniform depth, we have solutions in the form of harmonic modes

$$
\begin{aligned}
& \eta=A \cos (k x-\omega t), \quad u=B(z) \cos (k x-\omega t), \\
& v=C(z) \sin (k x-\omega t),
\end{aligned}
$$

where $\eta, u$ and $v$ are the surface elevation, the horizontal velocity component and the vertical velocity component, respectively. The wave number, $k$, is $2 \pi$ divided by the wavelength, $\lambda$, and $\omega$ is the frequency. For Eq. (1) to be a solution of the governing equations we must require that the wave number, $k$, and the frequency, $\omega$, fulfill the dispersion relation

$c^{2}=\frac{\omega^{2}}{k^{2}}=\frac{g}{k} \tanh (k h)$,

where $c$ is the phase speed, $g$ is the constant of gravity and $h$ is the equilibrium depth. Details on the derivation of Eq. (2) are found in many textbooks, such as Mei (1989). If compressibility is taken into account there exist other modes in addition to the pure gravity mode Eq. (2), which are generated by submarine earthquakes (see, for instance, Stiassnie, 2010 , and references therein). 
For long waves the dispersion relation may be expanded in terms of $k h$,

$c^{2}=c_{0}^{2}\left(1-\frac{1}{3}(k h)^{2}+\frac{2}{15}(k h)^{4}+O(k h)^{6}\right)$,

where $c_{0}=\sqrt{g h}$. Long-wave theories may be classified according to how much of the contents within the outer parentheses they reproduce. Shallow-water theory only yields the unitary constant, Korteweg-de Vries and standard Boussinesq equations inherit the first two terms, while optimized Boussinesq equations (such as Nwogu, 1993) also approximate the $O(k h)^{4}$ term. Also the model used herein may take the $O(k h)^{4}$ into account.

If we ignore the finite time duration of a submarine earthquake, together with compression waves in the water, the tsunami will evolve from an initial elevation, $\eta_{0}$, of the ocean surface, due to the seabed displacement. In a plane model this will give rise to two wave systems, which propagate in the positive and negative $x$ direction, respectively. For the system moving toward increasing $x$ values, Eq. (2) implies the solution

$\eta(x, t)=\frac{1}{2 \pi} \int_{-\infty}^{\infty} \hat{\eta}_{0}(k) e^{l(k x-\omega(k) t)} \mathrm{d} k$,

where $\hat{\eta}_{0}$ is the Fourier transform of $\eta_{0}$. Again we refer to standard textbooks, such as Mei (1989) or Whitham (1974). Near the wave front the long parts of the spectrum dominates and $\omega$ in Eq. (4) may be replaced by the first two terms $\omega \sim$ $c_{0} k\left(1-\frac{1}{6}(k h)^{2}\right)$.

The effect of dispersion will depend on the wavelengths, the depth and the time available for its evolution. Longterm evolution may also depend qualitatively on certain other properties of the initial condition, such as the net volume of displacement (see below). To find a simple relation we regard a group of initial conditions, which are of the same shape but have different lengths,

$\eta_{0}(x)=F\left(\frac{x}{\lambda}\right)$,

according to the value of the parameter $\lambda$. This gives $\hat{\eta}_{0}(k)=$ $\lambda \hat{F}(s)$, where $\hat{F}$ is the Fourier transform of the function $F$, and $s=k \lambda$. Using this, focusing on the wave propagating in the positive $x$ direction, and invoking the two-term expansion for $\omega$ in Eq. (4), we obtain

$\eta=G(\xi, \tau)=\frac{1}{2 \pi} \int_{0}^{\infty} \hat{F}(s) e^{l\left(\xi s+\frac{1}{36} \tau s^{3}\right)} \mathrm{d} s ;$

$\mathrm{d} s=\lambda \mathrm{d} k$, where the normalized variables,

$\xi=\frac{x-c_{0} t}{\lambda}, \quad \tau=\frac{6 c_{0} h^{2} t}{\lambda^{3}}$,

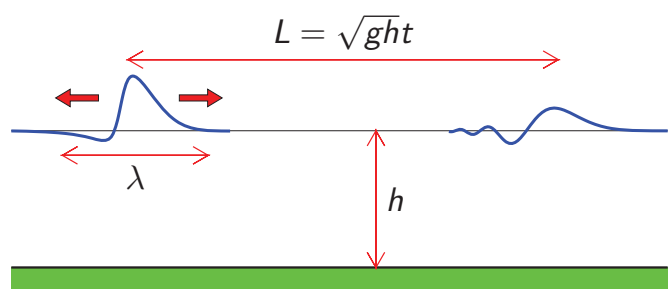

Fig. 1. Definition sketch of the evolution of an initial elevation from an earthquake.

are a translated spatial variable and a temporal variable for evolution of dispersion effects, respectively. Hence, we may regard $\tau$ as a "dispersion time". Below, we therefore use the term dispersion time when referring to $\tau$. Shallowwater theory corresponds to neglecting the second term in the expansion for $\omega$ in which case the solution immediately becomes $\eta=\frac{1}{2} F(\xi)$.

For large earthquakes, for instance, the behavior for finite and small $\tau$ is the most interesting (see Sect. 4). Dispersion then modifies the initial wave shape, while $\lambda$ still defines the length of the wave front. In such cases we may explain the significance of $\tau$ as follows. First, most of the energy in the spectrum is distributed on $k$ values ranging from zero to $2 \pi / \lambda$, say. In time $t$ the corresponding components will be displaced by an amount $\Delta c t$, where $\Delta c=c(0)-c(2 \pi / \lambda) \approx$ $6 c_{0} h^{2} / \lambda^{2}$. Then, this displacement must be measured against the length of the wave, $\lambda$. We then end with the dispersion time, $\tau$, in different forms

$\tau=\Delta c \cdot t \cdot \frac{1}{\lambda} \approx \frac{6 c_{0} h^{2}}{\lambda^{2}} \cdot t \cdot \frac{1}{\lambda}=\frac{6 h^{2} L}{\lambda^{3}}=\frac{6 h t}{g T^{3}}$,

where $L=c_{0} t$ and $T=\lambda / c_{0}$ are the propagation distance and the overall period, respectively (see Fig. 1). Naturally, the effect of dispersion accumulates in time and thus increases with $t$ and $L$. The variation is stronger with respect to $h$. However, the sensitivity is strongest with respect to the extension of the source, $\lambda$.

For large times $(\tau \rightarrow \infty)$ an asymptotic approximation for the wave front is found in textbooks (for instance, Mei, 1989). In the normalized coordinates this becomes

$\eta \sim \frac{\hat{F}(0)}{2(12 \tau)^{\frac{1}{3}}} \operatorname{Ai}\left(\frac{\xi}{(12 \tau)^{\frac{1}{3}}}\right)$,

where $\mathrm{Ai}$ is the Airy function. It is noteworthy that the initial condition only enters Eq. (8) through $\hat{F}(0)$, i.e. the initial volume per width of the disturbance divided by $\lambda$. At some distance behind the front Eq. (8) may be matched to the stationary phase approximation to yield a complete asymptotic expression for the evolution of plane waves at constant depth. The trailing waves attenuate proportional to $t^{-\frac{1}{2}}$ and the leading crest will eventually be dominant. From Eq. (8) 
we observe that the length of the leading crests increases with time. As a consequence the dispersive effects on this part of the wave system diminish, which is consistent with the fact that the relative attenuation rate of the wave height goes to zero. Therefore, dispersion may affect the wave front most strongly in the early parts of the propagation, while it later becomes relatively more significant in the trailing system of waves. It is thus stressed that while $\tau$ represents its accumulated effect, the significance of dispersion does by no means relate linearly to $\tau$ for larger dispersion times.

Another consequence of the stretching of the wave front is that nonlinearity becomes comparable with dispersion (Ursell's paradox, see Ursell, 1953). However, given the limited sizes of the oceans, the evolution of both dispersion and nonlinearity is too slow to reach this stage. Extra attenuation will reduce the significance of nonlinearity even further in the three-dimensional case (and remove Ursell's paradox).

If the net displaced volume is zero, then Eq. (8) no longer applies, but the leading crest height decays in proportion to $t^{-\frac{2}{3}}$ and its shape is defined by the derivative of the Airy function. In this case the trailing waves will eventually become dominant. Subduction earthquakes with dip angles between $0^{\circ}$ and $90^{\circ}$ will yield net elevation of the seafloor, implying that Eq. (8) is correct (see discussion in Kervella et al., 2007). Submarine landslides and slumps, on the other hand, are volume neutral, while subaerial landslides obviously yield a net positive volume. For partially subearial slides the net volume may be small in comparison to the total displaced volumes, and the waves may display an intermediate asymptotic attenuation, even for transoceanic propagation (see Løvholt et al., 2008). With two horizontal dimensions there is an additional attenuation due to geometrical spreading of the wave energy, introducing an extra attenuation factor of $t^{-\frac{1}{2}}$ for propagation distances much larger than the source extensions, and asymptotic analysis displays more diversity (see Mei, 1989).

In his profound study of tsunami generation and propagation, Kajiura (1963) reported many important derivations and observations. Among these the Fourier transforms given above are implicit, but another parameter was used for the significance of dispersion, namely

$P=\left(\frac{36}{\tau}\right)^{\frac{1}{3}}$.

Furthermore, it was suggested that dispersion has to be taken into account when $P<4$, which corresponds to $\tau \sim 0.5$ (see also Shuto, 1991, for a discussion). In view of the interpretation of $\tau$, as given above, this limit seems somewhat small in terms of $P$, and large in terms of $\tau$. Herein, we prefer to employ the dispersion time $\tau$ in our subsequent discussion on the influence of frequency dispersion, being a normalized time scale for evolution of dispersive effects.

Our identification of $\tau$ is made for constant depth. For variable depth we may exploit the invariance of the period, $T$, to suggest the integrated measure

$\tau=\frac{6}{g T^{3}} \int_{0}^{t} h \mathrm{~d} \hat{t}=\frac{6}{g T^{3}} \int_{0}^{L} \sqrt{\frac{h}{g}} \mathrm{~d} \hat{x}$.

In principle this expression requires slow variation of $h$ and integration along a ray path. Assuming an idealized geometry corresponding to a uniform slope stretching from the source region to the shoreline, we may estimate the coastal value of $\tau$ from Eq. (9):

$\tau=\frac{4 h_{0}^{2} L}{\lambda^{3}}$,

where $h_{0}$ is the depth in the source region, $\lambda$ is still the source width and $L$ is the distance from the source region to the shore. We observe that the reduction of dispersion due to shoaling alters the constant depth estimate in Eq. (7) only moderately.

Real disturbances may involve several length scales. For nonuniform sources we may have scales down to a few times the depth, as discussed by Løvholt et al. (2012) and Pedersen (2001). However, the leading wave will generally be dominated by the longest initial length scale, which then corresponds to $\lambda$. Still, the actual choice of $\lambda$ may be ambiguous.

\subsection{Combined nonlinearity and dispersion in shallow water: the undular bores}

In shoaling water the length-to-depth ratio of a tsunami increases and the dispersive effects are diminished; meanwhile the amplitude increases and nonlinear effects may become important. However, due to the nonlinearity the front of the tsunami steepens, which may lead to breaking or bring dispersive effects back into play. If the front width becomes comparable to depth while the amplitude-to-depth ratio is still less than 0.3, say, an undular bore evolves. In that case, long waves undergo fission into a series of individual peaks, of solitary shape, with height up to twice that of the wave before fission. Such bores are known to develop from tides in some rivers and estuaries, such as the Severn and the Garonne/Gironde, and have been observed for tsunamis as well. The phenomenon in relation to tsunamis was pointed out already by Shuto (1985), while more recent analysis and observations are given by, for instance, Madsen et al. (2008); Glimsdal et al. (2006); Grue et al. (2008); Arcas and Segur (2012) and references therein. The further dynamics of the undular bore may be complex, including breaking of the individual crest, with crucial loss of energy and even identity as separate waves as possible outcomes (Dorn et al., 1968; Korycansky and Lynett, 2005). It should be kept in mind that the evolution of undular bores requires an interaction between nonlinearity and dispersion and can thus not be reproduced in either nonlinear shallow water (NLSW) models or linear models. 


\section{Employed physical and mathematical models}

\subsection{Wave generation by earthquakes}

For seafloor deformation due to a coseismic single uniform slip we may immediately recognize a total width, $W$, and a length (along the fault), $B$, as length scales. According to earthquake scaling laws (e.g. Blaser et al., 2010; Leonard, 2010) $B$ is clearly larger than $W$. In addition, the deformation may contain shorter features, depending on the depth of the earthquake (e.g. Geist, 1998b; Mai and Beroza, 2002). Mathematical models for the deformation, such as Okada's formula (Okada, 1985), may even predict discontinuities. The presence of the accretionary wedge at the plate boundaries, etc., will replace the discontinuity by a transition of a finite length, which is still small compared to $W$, and even to the water depth. Splay faults or inhomogeneous fault distributions may introduce yet other short features in the source (e.g. Geist, 1998b). However, the short scales are not directly conveyed to the ocean surface. This may be due to finite duration effects of the earthquake that are difficult to assess, or to the hydrodynamic response to source distributions that does not produce surface responses with extensions less than a few depths, say (see, for instance, Kajiura, 1963; Pedersen, 2001; Løvholt et al., 2012b). Still, a common procedure for initiation of tsunami simulations is to copy the coseismic bottom deformation to the sea surface. This may lead to an unphysically high content of short-wave components in the tsunami spectrum. Even though these are sometimes dissipated numerically, the best option is to remove them in a sound and controlled manner. Representing the coseismic deformation as a source distribution at the bottom, we may compute the surface response. Herein, we employ two techniques for this. (1) By treating the source as a composition of narrow strips, normal to the fault line, we may employ two-dimensional models for the hydrodynamic response. For shallow earthquakes, with uniform slip, we may then employ an analytic expression, while a numerical integral is used otherwise (Pedersen, 2001; Løvholt et al., 2012). (2) We also compute the full three-dimensional response from an uplift distribution on the bottom. Assuming a rapid event, relative to the time gravity waves will spend crossing the source region, the sea surface elevation after the event will depend only on the final uplift distribution, $D(x, y)$, where $x$ and $y$ are the horizontal coordinates. For simplicity we employ Cartesian coordinates; the extension to geographical coordinates is straightforward. According to Kajiura (1963) the initial surface elevation at constant depth, $h$, then becomes

$\eta(x, y, 0)=h^{-2} \int_{-\infty}^{\infty} \int_{-\infty}^{\infty} D\left(x^{\prime}, y^{\prime}\right) G\left(\frac{\left|\boldsymbol{r}-\boldsymbol{r}^{\prime}\right|}{h}\right) \mathrm{d} x^{\prime} \mathrm{d} y^{\prime}$,

where $\boldsymbol{r}$ is the position vector, and the normalized Green function is given by
$G(r)=\frac{1}{2 \pi} \int_{0}^{\infty} \frac{m \mathrm{~J}_{0}(m r)}{\cosh m} \mathrm{~d} m=\frac{1}{\pi} \sum_{n=0}^{\infty} \frac{(-1)^{n}(2 n+1)}{\left\{(2 n+1)^{2}+r^{2}\right\}^{\frac{3}{2}}}$.

The function $G$ decays exponentially in its argument, and the integration intervals in Eq. (10) may be replaced by intervals of length $5 \mathrm{~h}$ centered at $x^{\prime}=x$ and $y^{\prime}=y$. At $\left|\boldsymbol{r}-\boldsymbol{r}^{\prime}\right|=$ $5 \mathrm{~h}$ we have $\frac{r}{h} G$ less than $10^{-3}$. For the case in Sect. 4.1 the application of such an integration interval leads to an error of less than $3 \times 10^{-4} \mathrm{~m}$, while the maximum uplift is roughly $1 \mathrm{~m}$. A table for $G$, covering the finite integration interval used in Eq. (10), is computed by means of the series in Eq. (11), and $G$ as a general function is then made available through interpolation.

We solve the equations for tsunami propagation on a regular grid in either geographic or Cartesian coordinates. The grid is staggered (Arakawa C type, see Pedersen and Løvholt, 2008; Mesinger and Arakawa, 1976) with surface nodes at $\boldsymbol{r}_{i, j}=(i \Delta x, j \Delta y)$, and the volume balance is observed for cells centered at these locations and with extensions equal to the grid increments. Denoting the average seabed elevation inside a cell by $D_{i j}$, the discrete counterpart to Eq. (10), at location $\boldsymbol{r}_{n m}$, becomes

$\eta_{n m}=\sum_{i} \sum_{j} \frac{\Delta x \Delta y}{h_{i j}^{2}} \sigma_{i j} D_{i j} G\left(\left|\boldsymbol{r}_{n m}-\boldsymbol{r}_{i j}\right| / h_{i j}\right)$,

where $\sigma_{i j}$ is a correction factor, explained below, $\Delta x$ and $\Delta y$ are the grid increments and only the contributions from a limited range in $i$ and $j$ need to be taken into account due to the exponential decay of $G$ in the far-field. In principle Eq. (12) is valid only for constant depth. However, if the depth variation over a distance of a few ocean depths is small in Eq. (12), this is a good approximation in nonuniform depth as well. The factor $\sigma_{i, j}$ is chosen as to preserve volume, in the sense that the contribution to the initial discrete surface elevation from cell $(i, j)$ equals $D_{i j} \Delta x \Delta y$. As long as the grid increments are well below the water depth in size, $\sigma_{i j}$ is very close to unity. If the grid increments are large compared to the water depth, on the other hand, then the volume correction procedure corresponds to copying the bottom deformation onto the sea surface.

A similar procedure as described above may also be employed at each time step for an event of finite duration, such as a landslide (see also Glimsdal et al., 2011).

The techniques for the hydrodynamic response and its smoothing effects on the initial condition is demonstrated in the first example, Sect. 4.1. A consequence of the smoothing effect is that sources at the bottom generate waves within the realm of Boussinesq equations. Naturally, waves generated in shallow water may still end outside the long-wave regime if they propagate into the deep ocean. Sources at the ocean surface, on the other hand, like impacting asteroids, rock slides plunging into water, and calving icebergs, may produce waves which are short compared to the depth. 
Shorter components in the spectrum (wavelengths down to a few depths, but still within the realm of Boussinesq equations) will propagate comparatively slower and influence the rear parts of the generated wave train. Hence, the evolution of the leading parts will mainly be governed by the long scales, namely $W$ or $B$, depending on the direction of wave advance. However, in a shallow-water solution shorter features will, artificially, also stay in the former part of the wave system, at least with a fine grid that yields weak numerical dispersion. Hence, as an indicator for the need of a dispersive model, $\tau$ should be based on the shortest significant length of the source. For the events presented below we have not included any particular information of shorter features, but generally compute the bottom deformation from Okada's formula applied to a single or a few faults. Then, for propagation normal to the fault line, which generally means toward land or off to sea, we identify the parameter $\lambda$ in Eq. (7) as the total width, $W$, of the slip region. On the other hand, for propagation in the direction parallel to the fault line the length, $B$, is the appropriate one. Since $B$ generally is much larger than $W$ we must expect the waves in the direction normal to the fault to display dispersion most strongly.

\subsection{Wave generation by landslides}

Considering a landslide simply as a uniform nondeformable block moving at a sub-critical speed (ignoring dispersion) reveals that the length of the landslide and duration of motion influence both the dominant wavelength and the surface elevation, while the thickness and the acceleration or deceleration of the landslide as well as the wave speed (which again is determined by the water depth) determine the surface elevation.

For numerical landslide tsunami models the simplest source model is a sink/source distribution with prescribed shape and kinematics ignoring the two-way landslide/water interaction. Presently, the tsunamigenic landslide models themselves apply simple rheological functions and ignore the multilayer structure of a submarine landslide with a dense debris flow at the bottom and a dilute turbidity current (suspension flow) above. Further, rock or mud type mass gravity flows will entrain water, and produce turbulence and large vortices that cannot be conveyed properly to a depth integrated model, while viscous drag may have a crucial influence on the shape and dynamics of the mudflow.

Rock slides plunging into fjords, lakes, or reservoirs evolve as super-critical and critical during impact, transitioning to sub-critical during the later phase of motion. The build-up of the wave persists as long as the Froude number is around unity. For rock slides, nonlinear effects may be important in the wave generation area, but often only in a restricted region and during a short period of time. Their tsunamigenic power is governed by the frontal area of the rock slide, the velocity of the rock slide when plunging into the water body, the permeability of the rock slide, and the bathymetry (see e.g. Harbitz et al., 2012b, and the references therein).

Quantification of the landslide parameters is complicated by the transformation of the landslide from solid to fluid and (in many cases) to a turbidity current. Another complicating factor is that many submarine landslides develop retrogressively, i.e. they are released progressively upwards from the slide toe (e.g. Kvalstad et al., 2005).

For the reasons above, we do not attempt to link $\lambda$ directly to the landslide parameters. Instead we extract it from the freshly generated wave as twice the distance, along a transect, between the first crest and the point at the front where the elevation is $10 \%$ of the height of this crest.

After the fashion described previously (Sect. 3.1) source features shorter than a few water depths may be filtered out also for landslides (Glimsdal et al., 2011).

\subsection{The tsunami propagation model}

The main model employed herein is an optimized version of the standard Boussinesq equations. The main features are

- Enhanced linear dispersion.

- Simpler and more efficient than FUNWAVE/COULWAVE for tsunami propagation purposes.

- Geographic coordinates or Cartesian coordinates.

- Rotational effects (Coriolis) included.

Denoting longitude and latitude by $\psi$ and $\phi$, respectively, we introduce dimensionless variables according to

$$
\begin{aligned}
& (\psi, \phi)=\Theta(x, y), \quad t=\frac{R \Theta}{\sqrt{g h_{0}}} \\
& (\hat{u}, \hat{v})=\epsilon \sqrt{g h_{0}}(u, v), \hat{h}=h_{0} h \quad \hat{\eta}=\epsilon h_{0} \eta,
\end{aligned}
$$

where the hats indicate variables with dimension, $g$ is the constant of gravity, $h_{0}$ is a characteristic depth, $R$ is the Equatorial radius of the Earth, and $\epsilon$ is an amplitude factor. The characteristic horizontal length (wavelength) now becomes $L_{\mathrm{c}}=R \Theta$, which may determine $\Theta$, and the "long-wave parameter" is accordingly recognized as

$\mu^{2}=\frac{h_{0}^{2}}{R^{2} \Theta^{2}}$.

For the physical constants we substitute

$g=9.81 \mathrm{~m} \mathrm{~s}^{-2}, \quad R=6378135 \mathrm{~m}$.

It is emphasized that these quantities are not constant, but their variation is neglected along with other small effects of rotation and the curvature of the Earth. We emphasize that the scaling given above allows us to state the Boussinesq equations in a transparent, custom manner. However, outside the present subsection we specify quantities in terms of physical units. 
In dimensionless variables the continuity equation reads

$c_{\phi} \frac{\partial \eta}{\partial t}=-\frac{\partial}{\partial x}\{(h+\epsilon \eta) u\}-\frac{\partial}{\partial y}\left\{c_{\phi}(h+\epsilon \eta) v\right\}-c_{\phi} \frac{\partial h}{\partial t}$,

where $c_{\phi}=\cos \phi$ is a map factor and the rightmost term, representing temporal bottom changes, is the source distribution from, for instance, a submarine landslide. By means of a surface response similar to the one described in Sect. 3.1 the field $\frac{\partial h}{\partial t}$ may be replaced by a slightly modified distribution.

The momentum equations are written as

$$
\begin{aligned}
\frac{\partial u}{\partial t}+ & \epsilon\left(\frac{u}{c_{\phi}} \frac{\partial u}{\partial x}+v \frac{\partial u}{\partial y}\right)=-\frac{1}{c_{\phi}} \frac{\partial \eta}{\partial x}+f v-\gamma \mu^{2} h^{2} \frac{1}{c_{\phi}} \frac{\partial D_{\eta}}{\partial x} \\
& +\frac{\mu^{2}}{2} \frac{h}{c_{\phi}^{2}} \frac{\partial}{\partial x}\left[\frac{\partial}{\partial x}\left(h \frac{\partial u}{\partial t}\right)+\frac{\partial}{\partial y}\left(c_{\phi} h \frac{\partial v}{\partial t}\right)\right] \\
& -\mu^{2}\left(\frac{1}{6}+\gamma\right) \frac{h^{2}}{c_{\phi}^{2}} \frac{\partial}{\partial x}\left[\frac{\partial}{\partial x}\left(\frac{\partial u}{\partial t}\right)+\frac{\partial}{\partial y}\left(c_{\phi} \frac{\partial v}{\partial t}\right)\right], \\
\frac{\partial v}{\partial t}+ & \epsilon\left(\frac{u}{c_{\phi}} \frac{\partial v}{\partial x}+v \frac{\partial v}{\partial y}\right)=-\frac{\partial \eta}{\partial y}-f u-\gamma \mu^{2} h^{2} \frac{\partial D_{\eta}}{\partial y} \\
+ & \frac{\mu^{2}}{2} h \frac{\partial}{\partial y}\left[\frac{1}{c} \phi \frac{\partial}{\partial x}\left(h \frac{\partial u}{\partial t}\right)+\frac{1}{c} \phi \frac{\partial}{\partial y}\left(c_{\phi} h \frac{\partial v}{\partial t}\right)\right] \\
& -\mu^{2}\left(\frac{1}{6}+\gamma\right) h^{2} \frac{\partial}{\partial y}\left[\frac{1}{c} \phi \frac{\partial}{\partial x}\left(\frac{\partial u}{\partial t}\right)+\frac{1}{c} \frac{\partial}{\partial y}\left(c_{\phi} \frac{\partial v}{\partial t}\right)\right],
\end{aligned}
$$

where $f$ is the Coriolis parameter and some smaller contributions to the convective acceleration terms are omitted. Equations valid for Cartesian grid are obtained simply by putting the map factor, $c_{\phi}$, to unity. The dispersion correction term, $D_{\eta}$, is the Laplacian of $\eta$ and was first proposed by Madsen and Sørensen (1992) with the coefficient $\gamma=-\frac{1}{15}$. We instead choose $\gamma=0.057$, which yields dispersion properties identical to those of Nwogu (1993). In Sect. 4.1, we will refer to this version of the model as "h.o.", because it is of higher-order with respect to dispersion properties, while the version with $\gamma=0$ is named "disp". The latter choice reproduces the so-called standard Boussinesq equations (Peregrine, 1967). Dispersion or nonlinear terms may be switched off independently. Further details on the model are given by Pedersen and Løvholt (2008); Løvholt et al. (2008, 2010). We emphasize that the model is fairly efficient. As an example we may state that the trans-Atlantic propagation of the La Palma tsunami on a $2^{\prime}$ grid (see Sect. 5.4) requires around $5 \mathrm{~h}$ of CPU time (on a single CPU) in a cheap off-the-shelf desktop.

\section{Seismic case studies}

\subsection{Portugal (1969)}

For some particular source configurations nonplanar extensions of Eq. (8) are available (see Mei, 1989; Clarisse et al., 1995). However, it is more instructive to study sources which are more realistic representations of submarine earthquakes. To this end we design a semi-idealized case inspired by a true event in the Atlantic Ocean south of the Iberian Peninsula in 1969.
This is an active seismic region, with the Lisbon earthquake of 1755 as the most prominent historical case. In 1969 an inverse thrust fault of magnitude $M_{\mathrm{w}}=7.9$ in the Horseshoe Abyssal Plain south of Portugal generated a moderate tsunami that was recorded at tide gauges in Portugal, Spain, and Morocco (Gjevik et al., 1997). The magnitude of the elevations from the model simulations (based on the seismic data) were consistent with the observed ones, even though there were unresolved issues concerning a single time series at Casablanca.

We assume a dip angle of $50^{\circ}$, an ocean depth $h=5 \mathrm{~km}$, a source width $W=50 \mathrm{~km}$, a length $B=100 \mathrm{~km}$ and a uniform slip of $2 \mathrm{~m}$. Combined with a shear modulus of $30 \mathrm{GPa}$, this yields a moment magnitude $M_{\mathrm{w}}=7.6$, which is somewhat lower than the one given above. Still, the case should be characteristic of moderately strong earthquakes with large dip angles. In Fig. 2 we have depicted the seabed displacement, as obtained from Okada's formula, and the surface response modified through Eq. (12), and compared the latter to the analytic expression by Pedersen (2001). The removal of the discontinuity and the shortest features is apparent, while the analytic expression and Eq. (12) are very similar in a transect through the center of the source $(y=0)$. The deviations are somewhat larger at outskirts of the fault line (results not shown). An obvious consequence of the modified sea surface elevation is a reduction of the shorter-wave components in the spectrum. In a dispersive model this will mainly affect trailing parts of the evolving wave patterns. On the other hand, in a shallow-water model the steep front, introduced by copying the seabed deformation directly to the surface, should in principle be retained. However, in numerical shallow-water models on coarse grids the numerical dispersion will remove the steep fronts and instead yield trailing noise.

In the present context we focus on properties for deep ocean propagation and employ an infinite ocean of depth $5 \mathrm{~km}$. Simulations have been performed for spatial resolutions $\Delta x=\Delta y=3.6 \mathrm{~km}, 2 \mathrm{~km}, 1 \mathrm{~km}$ and $0.5 \mathrm{~km}$. It is noted that the coarsest of these correspond to a $2^{\prime}$ resolution in geographical coordinates. In the present subsection, however, the resolution $\Delta x=0.5 \mathrm{~km}$ is used unless otherwise specified. The time step is determined by keeping the CFL number, $\sqrt{\mathrm{g} h} \Delta t / \Delta x$, equal to, or slightly smaller than, unity for dispersive simulations, while the CFL number is kept below 0.63 for shallow-water computations, since omission of the dispersive effects yields a stricter stability criterion (e.g. Pedersen and Løvholt, 2008). The slight variations in the CFL numbers with spatial resolution is due to the need to synchronize the simulations at intervals for comparison. After 1 hour of propagation the dispersive solutions for the three finest grids display relative deviations of order $0.5 \times 10^{-3}$ in the amplitudes of the leading crest, for propagation in the direction normal to the fault line. For the coarsest grid the error in this amplitude is increased to $5 \times 10^{-3}$, which is still rather small. In the rear part of the wave trains, where 

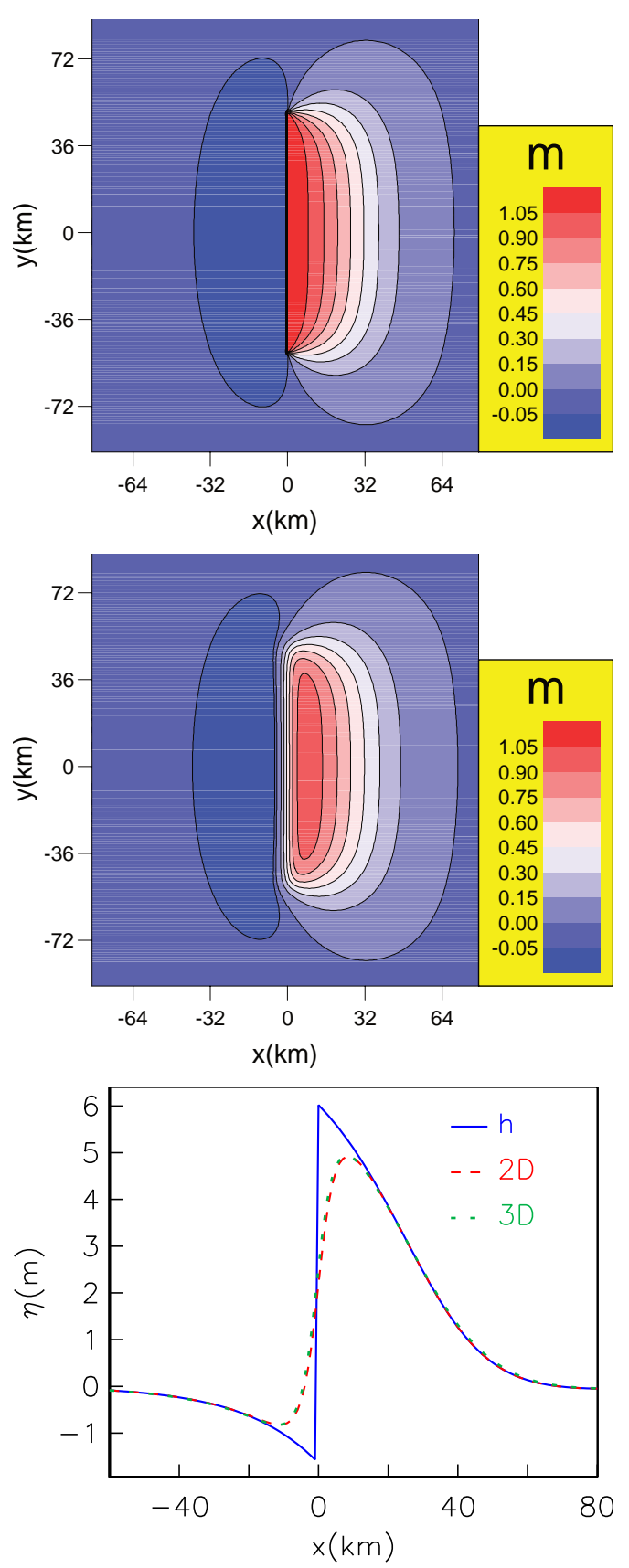

Fig. 2. Upper panel: seabed displacement. Mid-panel: the surface response as obtained by Eq. (12). Lower panel: comparison in the transect $y=0$ of seabed displacement $(h)$, surface profile from Eq. (12) (3-D) and surface profile from asymptotic formula of Pedersen (2001) (2-D).

the wavelengths are shorter, the grid dependence is much stronger. Examples of grid dependence in surface profiles are shown in Fig. 3. It is also remarked that the numerical dispersion is anisotropic and that the errors for propagation in directions oblique to the grid axis may be larger.

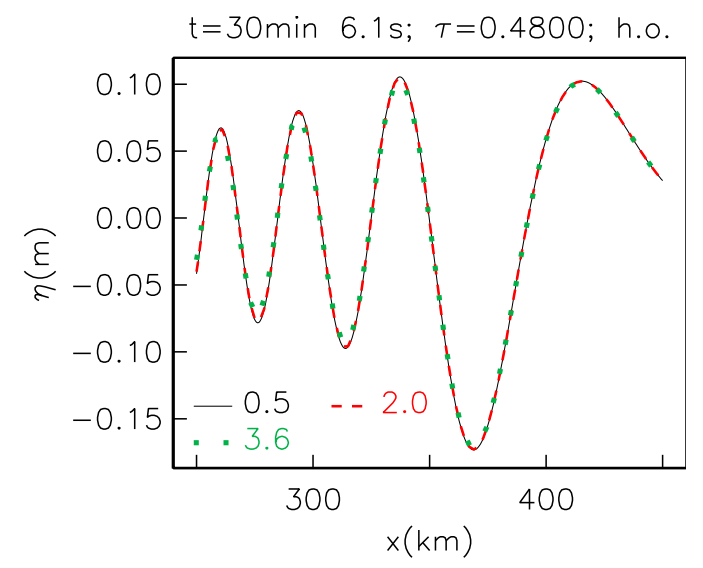

Fig. 3. The surface elevation along the $y=0$ transect after $30 \mathrm{~min}$. Results for different resolutions (given in $\mathrm{km}$ ) for the optimized Boussinesq model (h.o.) and initial conditions obtained with the Green function of Kajiura. Waves are propagating to the right.

For the leading part of the wave train the shallow-water solutions converge more slowly than the dispersive ones and are strongly affected by artificial dispersion for the coarser grids (results not shown).

In Fig. 4 we compare the surface elevation in the transect $y=0$, at $t=30 \mathrm{~min}$, for a dispersive simulation, starting with a copy of the seabed displacement on the surface to one where Eq. (12) has been applied. While the first crest is very similar for the two dispersive simulations, we clearly observe effects of the over-representation of shorter-wave components in the former solution in the trailing crests. In a corresponding study Dutykh et al. (2006) found larger differences for the leading crest, since they made the comparison at a much earlier time. The dispersion time, $\tau$, in the figure is close to 0.5 , the limit where dispersion effects should be taken into account according to Kajiura (1963). However, comparison with the hydrostatic linear shallow water (LSW) solution reveals that both the lengths and the heights of the leading crest and trough have been strongly altered by dispersion. Moreover, a significant trailing wave system has already developed in the dispersive solution, even for the smoother initial condition. This indicates that a criterion $\tau<0.5$ for applicability of shallow-water theory is too weak. For instance, the error of the LSW model may strongly affect an inversion of tsunami time series for the construction of a composite source. In their study of the 2009 Samoa event Zhou et al. (2012) employ a source which is composite, but still inherits scales consistent with $W=50 \mathrm{~km}$. According to their Fig. 3, which shows results for $\tau$ up to 0.3 , they experience a dispersive effect on the wave front comparable to the one in our Fig. 4. In Fig. 3 we display the grid dependence for the same time as is used in Fig. 4. We observe that the evolution of the first crests of the wave train is very similar for all displayed resolutions, even the coarsest with $\Delta x=3.6 \mathrm{~km}$. 


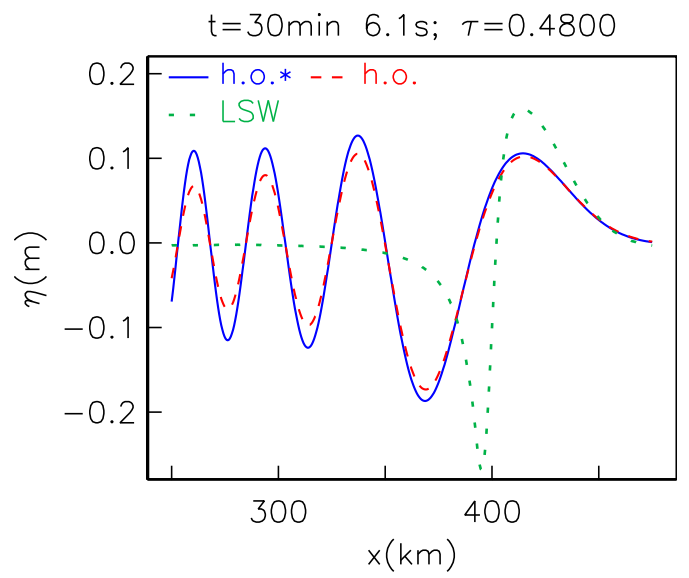

Fig. 4. The surface elevation along the $y=0$ transect after $30 \mathrm{~min}$. Dispersive results with initial conditions obtained with and without application of the Green function of Kajiura are marked h.o. and h.o.*, respectively. Also the LSW solution is included for comparison. Waves are propagating to the right.

In Fig. 5 the waves propagating in the positive $x$ direction are shown for $t \approx 7.5 \mathrm{~min}$ and $t \approx 1 \mathrm{~h}$. These times correspond to $\tau=0.12$ and $\tau=0.96$, respectively, where $\lambda$ is identified with $W=50 \mathrm{~km}$. Already at the earliest time the effect of dispersion is noticeable, while it has transformed the wave train crucially at $t \approx 1 \mathrm{~h}$, when the only quantity properly reproduced by the LSW equations is the arrival time. The standard and higher order dispersion representation only makes an apparent difference late in the emerging wave trains. We also observe that the second crest is slightly higher than the leading one in the dispersive solutions. This is a three-dimensional effect that is neither observed for the train propagating in the negative $x$ direction nor in the plane simulations (below). However, nonuniformity of the source, constructive interference of reflections, and/or formation of undular bores are presumably more likely reasons for the larger inundation of secondary waves observed in true tsunami cases.

The behavior for waves propagating in the $y$ direction is quite different. Transect results after one hour are shown in Fig. 6 and we observe only moderate effects of dispersion. In this case the "dispersion time", $\tau$, is based on $\lambda=B=$ $100 \mathrm{~km}$, which gives a value $\tau=0.12$ corresponding to that for the upper panel in Fig. 5. The dispersion effects in the two graphs also appear to be of the same magnitude.

We conclude this introductory example by reporting some plane simulations, with the transect profile in Fig. 2 as initial condition. For the wave system propagating in the positive $x$ direction we observe that the leading crest is fairly well described by the asymptotic formula (8) after one hour of propagation, while the match is nearly perfect after two hours (Fig. 7). This implies that the original source length has become irrelevant at this stage.
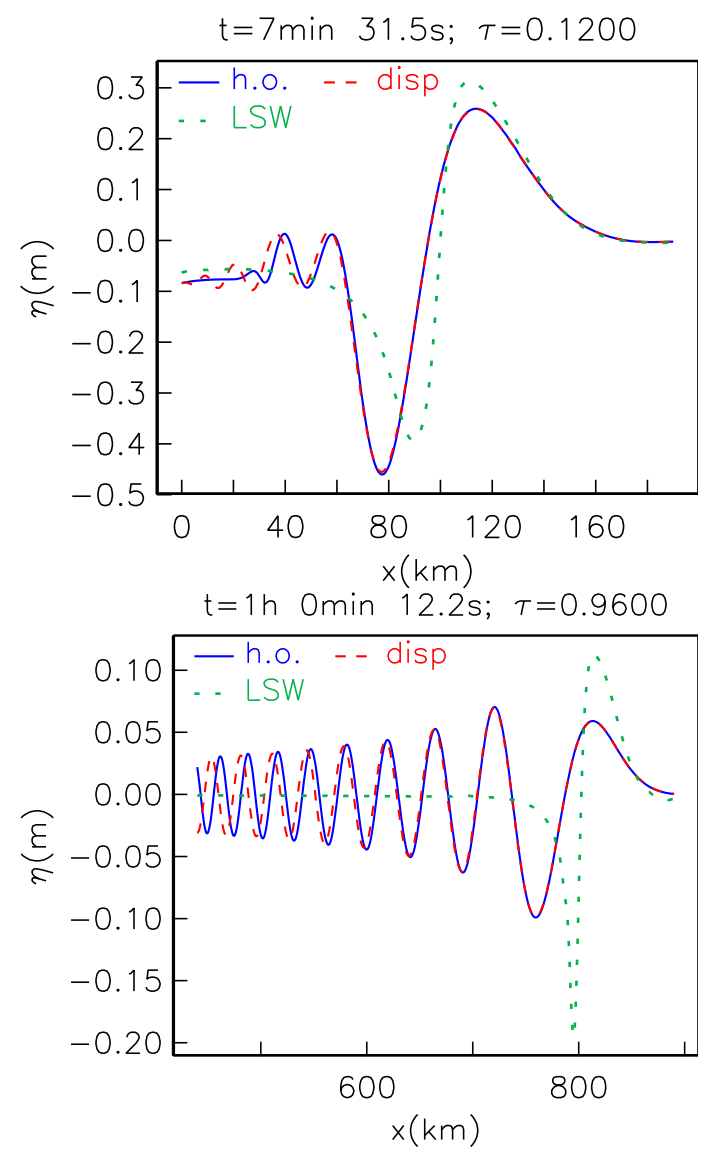

Fig. 5. The surface elevation along the $y=0$ transect, for the wave system propagating in the positive $x$ direction. Results obtained from models with standard and enhanced dispersion properties are marked by "disp" and "h.o", respectively. Waves are propagating to the right.

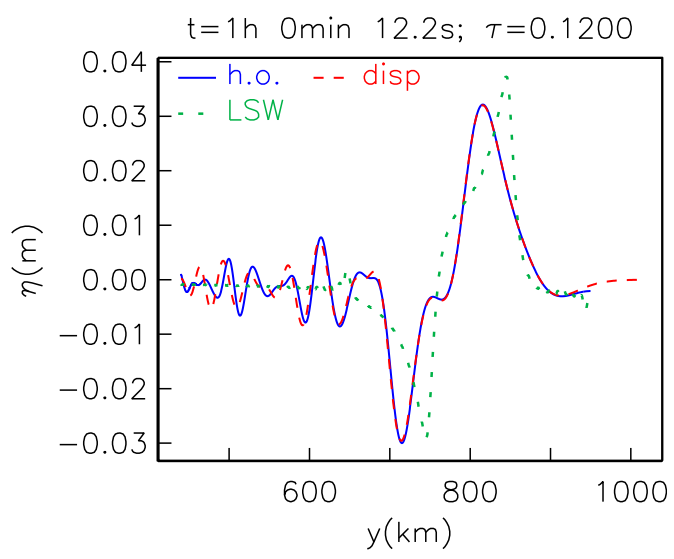

Fig. 6. The surface elevation along the $x=0$ transect. Waves are propagating to the right. 

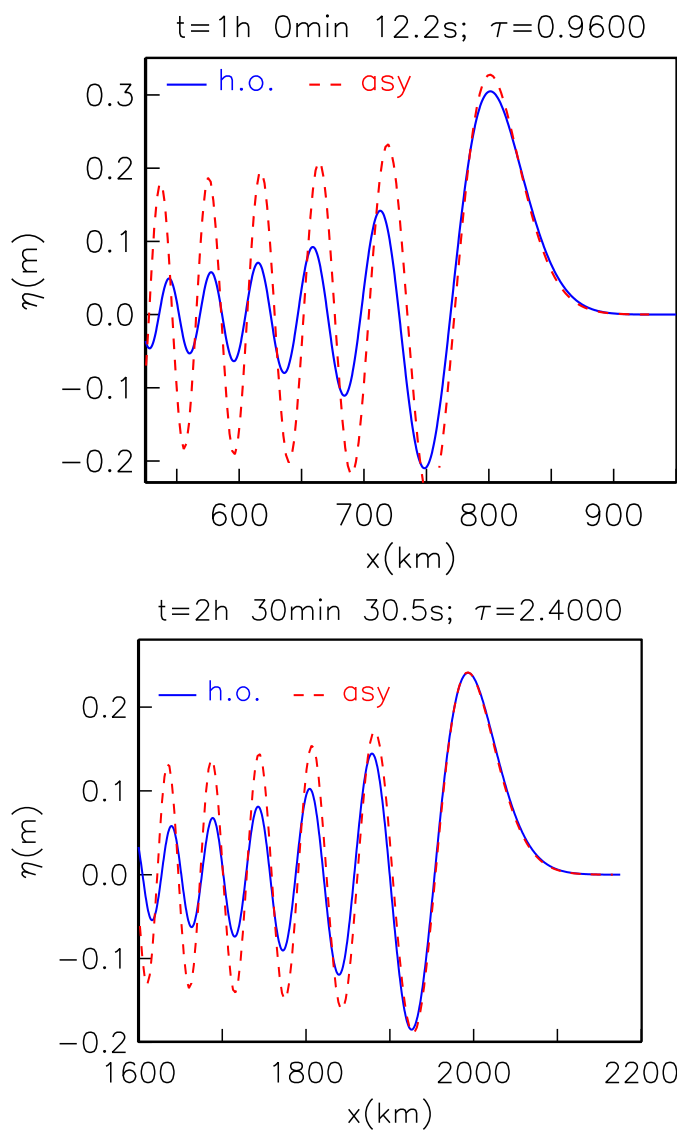

Fig. 7. The surface elevation for plane simulations. Comparison of dispersive simulation (h.o.) and the asymptotic formula (8) for the wave front. The phase of the latter is adjusted to yield coinciding leading peaks at $t=37.5 \mathrm{~min}$. Waves are propagating to the right.

\subsection{Indian Ocean tsunami (2004)}

Here we investigate the effect of dispersion for the 26 December 2004 Indian Ocean tsunami. The rupture started around latitude $3^{\circ} \mathrm{N}$ and continued about $1200 \mathrm{~km}$ northward along the Sunda Trench. The width of the source was about $200 \mathrm{~km}$ and the maximum slip was about $20 \mathrm{~m}$. The earthquake had a magnitude of $M_{\mathrm{w}}=9.0$ and a dip angle of about $15^{\circ}$ (e.g. Bilham, 2005; Stein and Okal, 2005).

Glimsdal et al. (2006) found an insignificant effect of dispersion close to the earthquake. However, for longer propagation distances, the effect of dispersion was found to be more apparent. In Fig. 8 the linear hydrostatic and linear dispersive solutions are shown along a transect towards Africa at a distance of $4300 \mathrm{~km}$ from the source area. With an average sea depth of $4000 \mathrm{~m}, W=200 \mathrm{~km}$ and $B=1200 \mathrm{~km}$, the dispersive parameter is $\tau \sim 0.05$. The solutions differ mostly in shape/steepness of the leading wave. The grid resolution in the computations was $2^{\prime}$.

In many videos and photos taken of the tsunami, short features are evident (e.g. Arcas and Segur, 2012). A possible

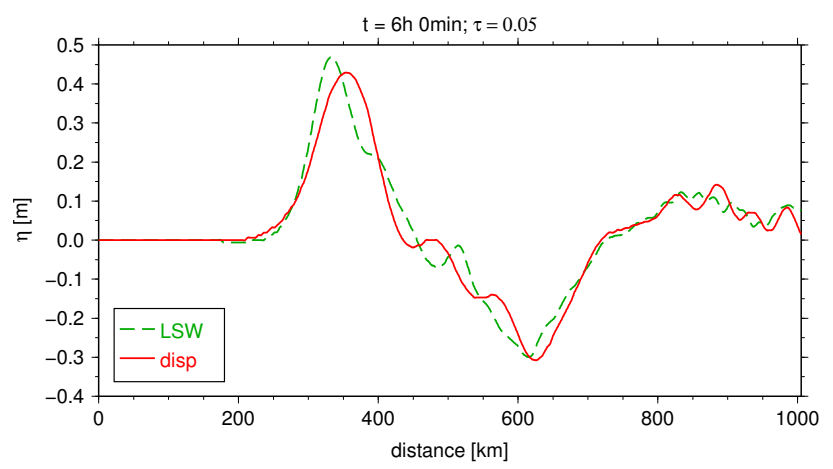

Fig. 8. The linear hydrostatic and linear dispersive solutions of the Indian Ocean tsunami towards Africa extracted along a transect with length $1000 \mathrm{~km}$ (surface elevations). Waves are propagating to the left.

explanation is that the front of the tsunami in certain places evolved into an undular bore. Glimsdal et al. (2006) and Grue et al. (2008) showed through simulations towards Malaysia (Malacca Strait) that undular bores may be formed.

\subsection{Japan (2011)}

The 11 March 2011 Tohoku tsunami devastated the east coast of Japan and caused almost 20000 fatalities. The earthquake with a magnitude $M_{\mathrm{W}}=9.0$ occurred $130 \mathrm{~km}$ east of the Sendai coast, Japan. The source extensions were $B=400 \mathrm{~km}$ and $W=150 \mathrm{~km}$. The average slip was reported to be $15-$ $20 \mathrm{~m}$ with a maximum value exceeding $60 \mathrm{~m}$ (e.g. Lay et al., 2011; Ozawa et al., 2011). To model the tsunami we apply an earthquake source with a nonuniform slip distribution, a maximum slip of $20 \mathrm{~m}$, and a dip angle of $25^{\circ}$ (see Løvholt et al., 2012b).

The modeled surface elevations are compared to the registered data from DART buoys (http://www.ndbc.noaa.gov-/ dart.shtml). In Fig. 9 the maximum surface elevation for the Pacific Ocean is shown together with the locations of selected DART buoys. In the same figure the mariograms for both the numerical model and the measurements at DART buoys 21401 (about $1000 \mathrm{~km}$ northeast of the source area), 51407 (Hawaii), and 43413 (west of Guatemala) are found. The comparison to the DART buoy data shows that the tsunami was clearly affected by dispersion at buoy 43413 , but also at 51407 . At DART buoy 43413 the height of the leading wave for the dispersive solution is close to the measured one, while the linear hydrostatic solution overestimates the measured height by as much as $\sim 30 \%$. At this buoy we found that $\tau \sim 0.45$, with an average sea depth from the source to the buoy of $4.7 \mathrm{~km}$. At buoy 51407 the effect of dispersion is still clear (but slightly reduced), while there are no visible effects of dispersion at 21401. Note that the results from the DART buoys are given a shift of up to $200 \mathrm{~s}$, to match the arrival of the leading peak in the simulations and make the 

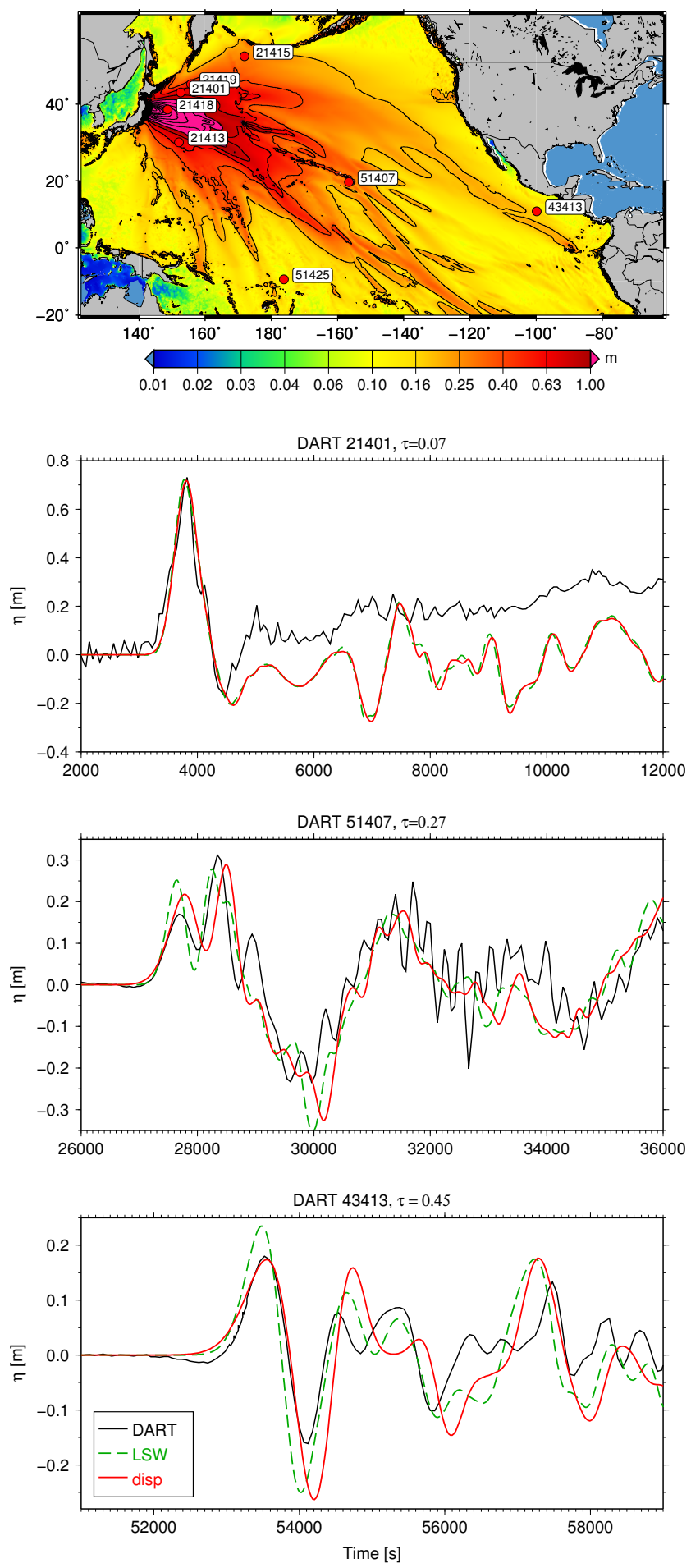

Fig. 9. The Tohoku tsunami 2011. In the upper panel the maximum surface elevation for the Pacific Ocean is shown. In the lower panels the mariograms (for three of the DART buoys) for the computed surface elevations for the linear shallow water ("LSW") and linear dispersive ("disp") solutions are compared to the measured surface elevations ("DART”). comparison easier. The measurements at DART buoy 21418 is coarse and influenced by noise; the maximum value of the leading peak is therefore somewhat uncertain. This is the reason why the results from buoy 21401 are plotted instead of buoy 21418 located in front of the source area. The comparison between the numerical solutions and the measured data from eight DART buoys are elaborated in upon Table 1. The overall picture is not entirely clear and may be influenced by directivity and the nonuniform source distribution. Still, there is a tendency for increasing importance of dispersion for long-distance propagation. The resolution of the computational grid was $4^{\prime}$. Grid refinement tests at buoy 21413 comparing the results from a $4^{\prime}$ grid with those from $2^{\prime}$ and $1^{\prime}$ grids, covering a smaller part of the Pacific Ocean, show a difference in the height of the leading wave of less than $1 \%$ for LSW and $0.5 \%$ for the linear dispersive solution.

\subsection{Potential earthquake at Lesser Antilles}

NE of Guadeloupe in the Caribbean, we have modeled a potential earthquake with magnitude $M_{\mathrm{w}}=8.0$ (for details, see e.g. Løvholt et al., 2010; Harbitz et al., 2012a). The dip angle is $80^{\circ}$. The grid resolution was $0.5^{\prime}$. The earthquake source lies along a SSE-NNW axis with a depression facing to the ENE, as shown in Fig. 10. The effect of dispersion is investigated through mariograms at two locations. The first location is $350 \mathrm{~km}$ south of the earthquake (outside Bridgetown, Barbados) and the second location is about $350 \mathrm{~km}$ to the east. In the first case the direction of propagation is close to the azimuth direction of the source, and we therefore set $\lambda=B=150 \mathrm{~km}$, and the average depth to $3 \mathrm{~km}$. In the second case we look at propagation mainly along the dip direction, and set $\lambda=W=50 \mathrm{~km}$, and the average depth to $5 \mathrm{~km}$. The mariograms show that the effect of dispersion is almost absent for the laterally propagating leading waves for location 1 ( $\tau=0.006)$, while the effects of dispersion at location 2 is crucial $(\tau=0.42)$. Hence, source orientation and location govern influence of frequency dispersion.

\subsection{Potential earthquake at the Hellenic Arc}

As an example from the Mediterranean, we show the tsunami for a potential earthquake SW of Crete (for details, see e.g. Løvholt et al., 2012a). The earthquake has a magnitude $M_{\mathrm{w}}=7.8$ and a dip angle of $15^{\circ}$. The extensions of the source correspond to $B=100 \mathrm{~km}$ and $W=44 \mathrm{~km}$. As in the example from the Lesser Antilles above, we evaluate the effect of dispersion along transects after $10 \mathrm{~min}$. The dispersive parameter is calculated when the leading waves have propagated a distance of $180(h=1.7 \mathrm{~km})$ and $250 \mathrm{~km}(h=2 \mathrm{~km})$ along the transects ahead (to the south) and laterally, respectively. In Fig. 11 solutions along these two transects are shown. Laterally the effect is very limited with $\tau=0.006$, while ahead of the fault the effect of dispersion is clearer, but still small, with $\tau=0.036$. The grid resolution was $0.5^{\prime}$. 
Table 1. The values of $\tau$ for eight different DART buoys, together with the simulated (linear hydrostatic - "LSW"; and linear dispersive "disp") and measured ("DART") height of the leading wave. $L$ is the propagation distance, $t$ is the propagation time, while $\bar{h}$ is the average sea depth (calculated by using $t$ and the LSW propagation speed, $\sqrt{g \bar{h}}$ ). (DART 21418 - uncertain value due to coarse resolution of the data.)

\begin{tabular}{lccccccc}
\hline DART \# & LSW [m] & disp [m] & DART $[\mathrm{m}]$ & $L[\mathrm{~km}]$ & $t[\mathrm{~h}]$ & $\bar{h}[\mathrm{~km}]$ & $\tau$ \\
\hline 21401 & 0.72 & 0.72 & 0.73 & 1000 & 1.1 & 6.3 & 0.07 \\
21413 & 0.64 & 0.68 & 0.78 & 1200 & 1.3 & 5.8 & 0.07 \\
21415 & 0.27 & 0.26 & 0.28 & 2700 & 3.1 & 5.9 & 0.17 \\
21418 & 1.78 & 1.80 & $1.86^{*}$ & 500 & 0.5 & 6.3 & 0.04 \\
21419 & 0.51 & 0.51 & 0.56 & 1300 & 1.3 & 6.8 & 0.11 \\
51407 & 0.25 & 0.21 & 0.17 & 6000 & 7.5 & 5.0 & 0.27 \\
51425 & 0.07 & 0.07 & 0.06 & 7000 & 8.1 & 5.7 & 0.40 \\
43413 & 0.23 & 0.17 & 0.18 & 11500 & 14.7 & 4.7 & 0.45 \\
\hline
\end{tabular}
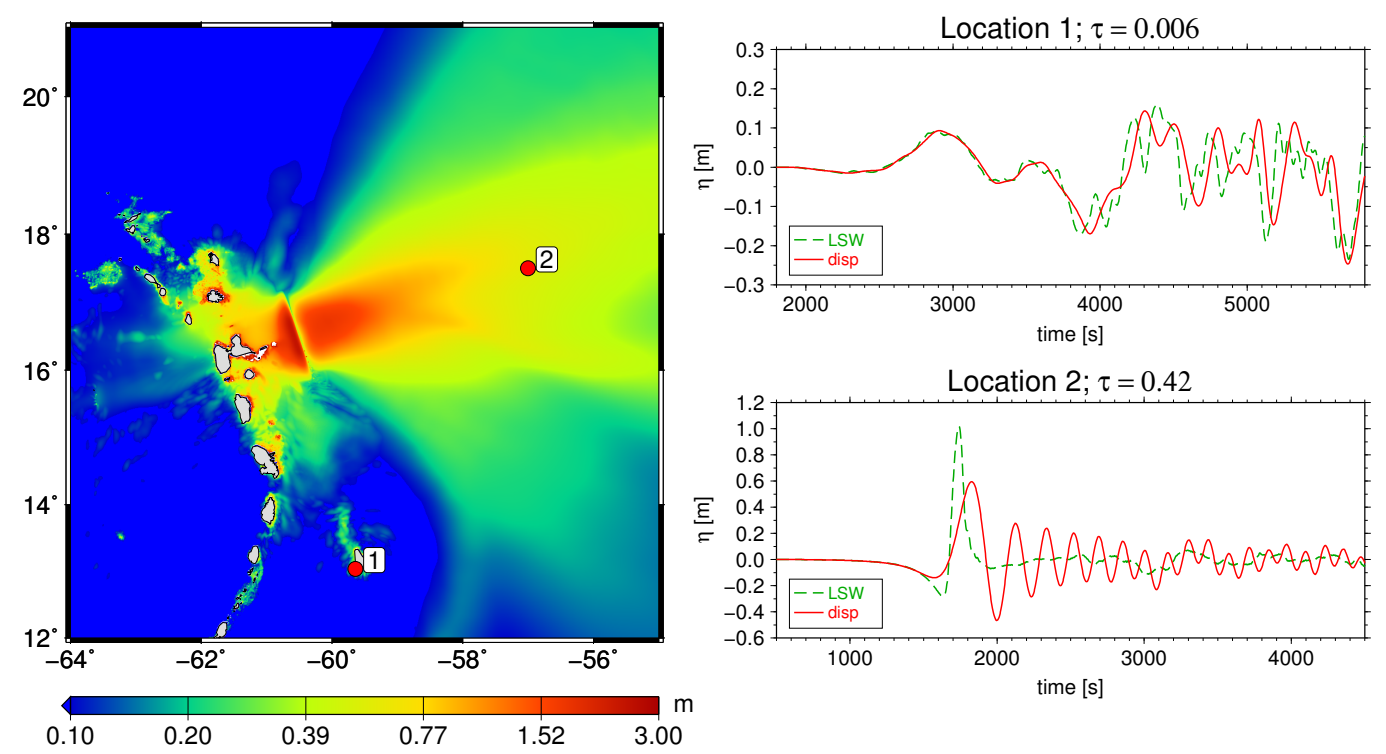

Fig. 10. The maximum surface elevations for the linear hydrostatic solution is shown to the left. The locations of the mariograms are indicated with the numbers 1 and 2, with the corresponding results shown in the upper and lower right panels.

\subsection{Dispersive effects on seismic tsunamis, worldwide}

A global study of tsunami impact is presented in Løvholt et al. (2012a). In Table 2 we present the dispersive parameter for a selection of the earthquake sources from this study in order to demonstrate practical examples of the dispersion number for forecasting. The parameter $\tau$ is estimated by substituting a propagation distance of $L=1000 \mathrm{~km}$, an average depth and a source width into Eq. (7). Both the source width and the depth are given in the table. Again we see that the smaller earthquakes with narrow width are expected to be much more affected by dispersion - see e.g. the earthquake along the Makran fault (Pakistan) with $\tau \sim 0.9$. The mega-earthquakes, in particular, have much smaller $\tau$ and are hence expected to be less affected by dispersion - see e.g. the $M_{\mathrm{W}}=9.4$ outside southern Chile with $\tau \sim 0.01$. The intermediate cases need to be evaluated individually with respect to dispersive effects.

\section{Landslide-generated tsunamis}

\subsection{The Storegga submarine landslide}

The Storegga Slide on the continental slope off Western Norway around $8150 \mathrm{yr} \mathrm{BP}$ is one of the largest and best-studied submarine landslides on Earth (Bugge et al., 1987, 1988; Haflidason et al., 2004; Bryn et al., 2005; Kvalstad et al., 2005). The landslide comprised a volume of about $2400 \mathrm{~km}^{3}$. Today, the most common view is that the Storegga Slide was a continuous retrogressive process, and deposits of the corresponding giant tsunami are found in Norway, Faroe Islands, Shetland and Scotland (Harbitz, 1992b; Bondevik et al., 
Table 2. Values for the dispersive parameter $\tau$ for a selection of sources applied in Løvholt et al. (2012a). $\tau$ is measured at a distance of $1000 \mathrm{~km}$ away from the source. The earthquake source parameters: $M_{\mathrm{W}}-$ magnitude; $B-$ length; $W-$ width; and $D-$ dip angle. $\bar{h}$ is the average sea depth used for estimation of $\tau$. Abbreviations: SA - Sunda Arc; BF - Burma Fault; MF - Makran Fault; BA - Banda Arc; NGT - New Guinea Trench; PT - Philippine Trench; TT - Tonga Trench; SST - South Solomon Trench; NHT - New Hebrides Trench; PCT Peru-Chile Trench; PRT - Puerto Rico Trench; HA - Hellenic Arc.

\begin{tabular}{lcccccc}
\hline Location & $M_{\mathrm{W}}$ & $B[\mathrm{~km}]$ & $W[\mathrm{~km}]$ & $D[\mathrm{deg}]$ & $\bar{h}[\mathrm{~km}]$ & $\tau$ \\
\hline SA, Andaman Islands & 8.50 & 362 & 100 & 15 & 5 & 0.150 \\
SA, South Sumatra & 9.10 & 527 & 200 & 15 & 5 & 0.019 \\
BF, Myanmar - Bangladesh & 8.90 & 655 & 125 & 10 & 3 & 0.028 \\
MF, Pakistan coast & 8.40 & 398 & 48 & 10 & 4 & 0.868 \\
BA, Eastern Banda Sea & 8.50 & 261 & 150 & 20 & 3 & 0.016 \\
NGT, Eastern Irian Jaya & 8.50 & 258 & 100 & 20 & 4 & 0.096 \\
PT, South Mindanao & 8.40 & 176 & 100 & 20 & 5 & 0.150 \\
MT, Western Luzon & 8.20 & 348 & 70 & 45 & 5 & 0.437 \\
TT, Northern part & 9.00 & 519 & 200 & 20 & 5 & 0.019 \\
SST, Eastern Solomon Isl. & 8.30 & 281 & 100 & 20 & 5 & 0.150 \\
NHT, Southern Vanuatu & 8.60 & 314 & 100 & 20 & 3 & 0.054 \\
NHT, Northern Vanuatu & 8.60 & 340 & 100 & 20 & 3 & 0.054 \\
PCT, Southern Chile & 9.40 & 853 & 200 & 20 & 4 & 0.012 \\
PRT, North Hispaniola & 8.00 & 200 & 55 & 80 & 5 & 0.902 \\
HA, South of Crete & 7.70 & 149 & 75 & 20 & 3 & 0.128 \\
\hline
\end{tabular}
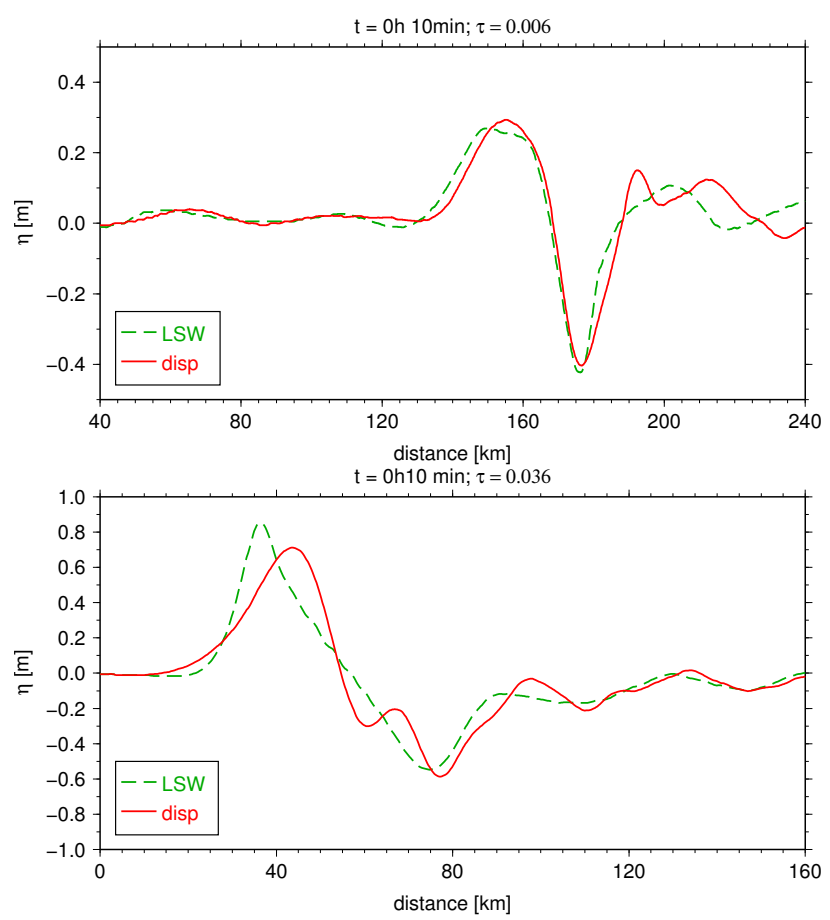

1997a,b, 2005; Dawson et al., 1988). Best agreement with the observations is obtained with a maximum frontal velocity of $25-30 \mathrm{~m} \mathrm{~s}^{-1}$, a run-out distance of the dense tsunamigenic flow of $150 \mathrm{~km}$, and a retrogressive release of the total volume lasting less than one hour, i.e. 15-20 s between the releases of each individual landslide element (Bondevik et al., 2005). The Storegga Slide tsunami is composed exclusively by very long components relative to the water depth. Moreover, the propagation distances in the Nordic Seas are fairly limited. As a result, the Storegga Slide tsunami illustrates that dispersion is insignificant for waves generated by large and sub-critical submarine landslides with moderate acceleration and deceleration dominated by wave components much longer than the water depth (Haugen et al., 2005). In terms of the dispersive parameter we find $\tau \sim 10^{-4}$ at a distance of $200 \mathrm{~km}$ towards Norway. Even for a propagation distance of $4000 \mathrm{~km}$ towards North America the value of $\tau$ is relatively small, $\tau=0.04$. The numerical simulations (linear hydrostatic only) is performed on a grid with a resolution of about $2 \mathrm{~km}$.

\subsection{The Hinlopen submarine landslide}

For the pre-Last Glacial Maximum Hinlopen Slide at the mouth of the Hinlopen cross-shelf trough on the northern Svalbard margin, bathymetric effects as well as high speed and huge thickness of the dislodged mass and the rafted blocks probably implied that shorter-wave components introducing dispersive and nonlinear effects were more pronounced than for most other tsunamis generated by submarine landslides (Vanneste et al., 2011). The headwall is several hundred meters high (exceeding $1400 \mathrm{~m}$ ). Despite 

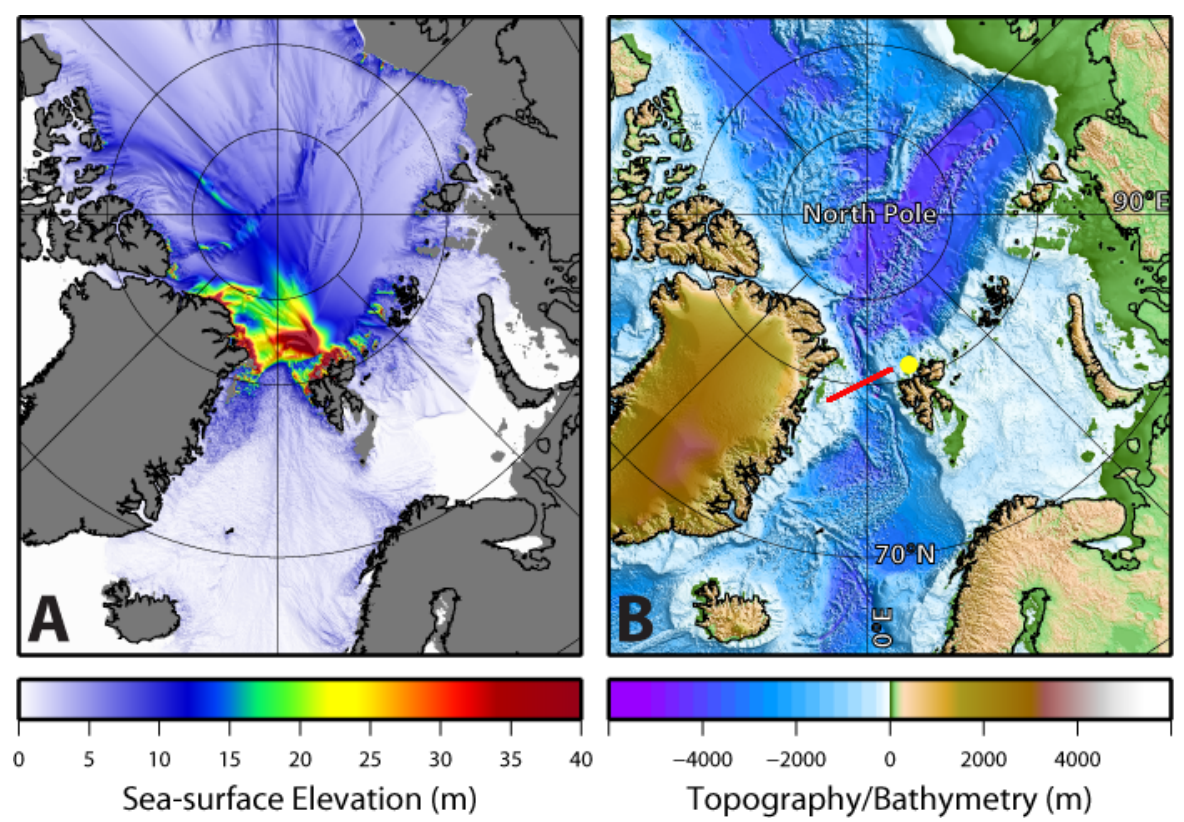

Fig. 12. The tsunami after the Hinlopen submarine landslide. Panel A shows the maximum surface elevation of the generated tsunami. Values above $40 \mathrm{~m}$ are colored red. The bathymetry is shown in (B), where the initial posistion of the landslide (yellow point) and the transect for Fig. 13 (red line) are shown. The figure is modified from Vanneste et al. (2011).

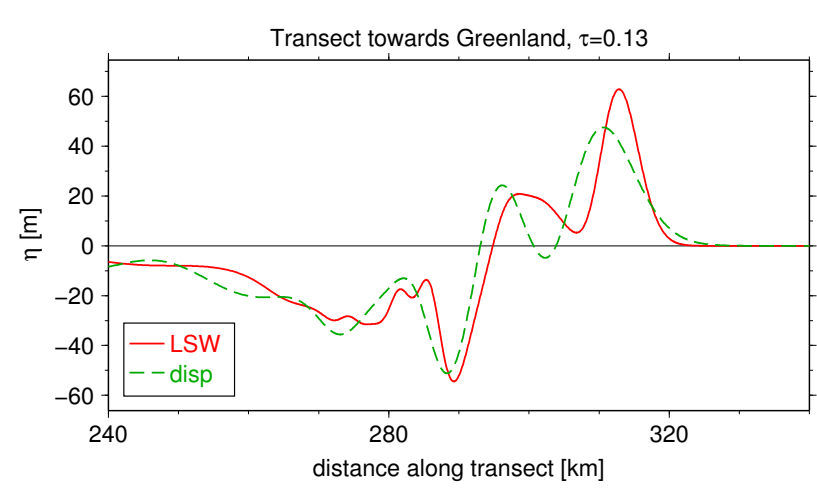

Fig. 13. Computations of the waves generated by the Hinlopen submarine landslide along a transect towards Greenland. The front of the waves has traveled $420 \mathrm{~km}$ from the landslide area over an average depth of about $2 \mathrm{~km}$. Waves are propagating to the right (southwest).

the relatively small slide scar area (about $5 \%$ of the size of the Storegga Slide area), an upper estimated volume of about $1350 \mathrm{~km}^{3}$ (about $55 \%$ of the Storegga Slide volume) was excavated from the northern Svalbard continental margin (Vanneste et al., 2011). Close to the slide area the simulations of the tsunami show surface elevations over $130 \mathrm{~m}$, whereas the tsunami may have been several tens of meters along the coasts of Svalbard and Greenland. The dispersive effects and the radial spread reduce the maximum surface elevations as the tsunami propagates out from the slide area. A simulation along a transect towards Greenland is shown in Fig. 13. The effect of dispersion is here clear with $\tau=0.13$.

\subsection{Papua New Guinea (1998)}

The 1998 Papua New Guinea (PNG) tsunami gave run-up heights up to $15 \mathrm{~m}$ and affected a $20 \mathrm{~km}$ segment of the coast, killing 2200 people (Dengler and Preuss, 2003; McSaveney et al., 2000). Farther away the tsunami was not a significant event (Okal and Synolakis, 2004).

Initially, the tsunami was believed to originate from an earthquake. However, attempts to model the tsunami using solely an earthquake source gave too-small amplitudes and too-late arrival times (e.g. Geist, 1998a). It is broadly accepted that the damaging part of the tsunami was due to a slump (Bardet et al., 2003; Tappin et al., 2003; Sweet and Silver, 2003), while the earthquake was responsible for the far-field tsunami and played an indirect role as the slump triggering mechanism.

The dipole shape and the short-wave components of the generated waves contribute to radial spreading (Okal and Synolakis, 2004) and frequency dispersion (Lynett et al., 2003), respectively, which reduce the surface elevation in the far-field. From Synolakis et al. (2001) we found $\lambda=10 \mathrm{~km}$, according to Sect. 3.2, and the propagation towards land, about $20 \mathrm{~km}$ away, gave $\tau \sim 0.1$ (moderate effect of dispersion). At a distance of $50 \mathrm{~km}$ offshore $\tau \sim 5$, which means that the effect of dispersion was crucial. On the other hand, 

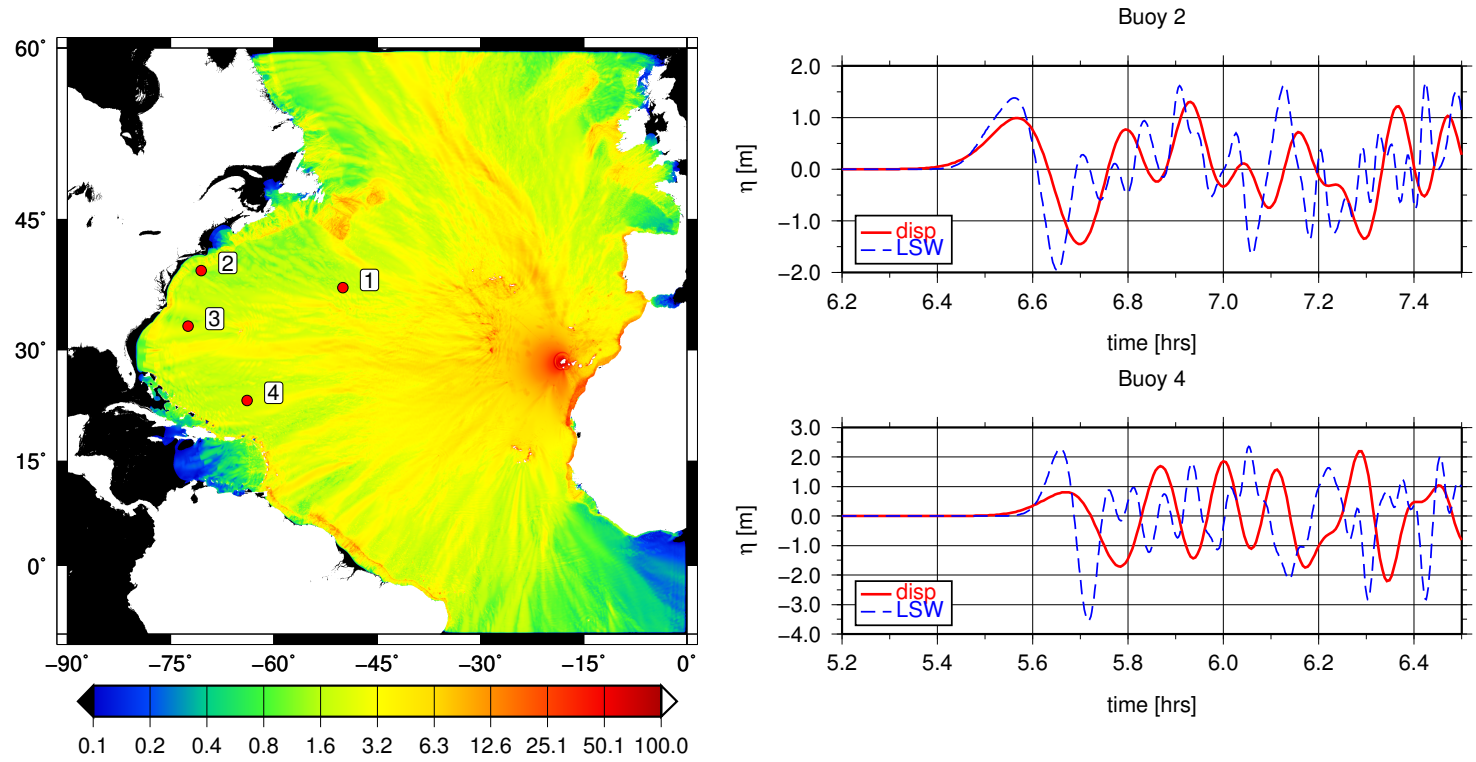

Fig. 14. The La Palma tsunami. Left panel: maximum wave elevation and position of buoys. Right panels: time series at two buoy locations.

it is noteworthy that Lynett et al. (2003) reported that even though dispersion had a crucial effect on the incident wave, the flooding was rather similar to the one obtained by a NLSW model. It is not clear whether this is circumstantial or a more general feature.

\subsection{Potential landslide from La Palma}

A potential massive volcanic flank collapse at La Palma Island was first suggested by Ward (2001). Assuming a slide volume of $500 \mathrm{~km}^{3}$, they predicted wave heights along the east coast of North America in the range 10-25 m. However, this extreme scenario has remained controversial ever since. Masson et al. (2002); Wynn and Masson (2003); Masson et al. (2006); Hunt et al. (2011) questioned the geological aspects, while Mader (2001); Gisler et al. (2006) obtained much smaller waves in the far-field.

In Gisler et al. (2006) the slide volume was reduced to $375 \mathrm{~km}^{3}$. The wave generation and early propagation were treated with the multimaterial SAGE model, while the farfield estimates were obtained by extrapolation of local attenuation rates. Løvholt et al. (2008) started with the near-field solution of Gisler et al. (2006), but treated the oceanic propagation with a set of Boussinesq type equations. By this procedure they obtained wave heights at the American coast that were slightly smaller than those of Ward (2001), but still dangerous. Recently, Abadie et al. (2012) applied a similar strategy, with a slide volume of $500 \mathrm{~km}^{3}$, and obtained somewhat higher waves close to the Canary Islands than Løvholt et al. (2008). However, they did not compute the trans-Atlantic propagation. The La Palma tsunami case is also studied by Zhou et al. (2011).
We omit most of the details on the wave field in Løvholt et al. (2008) and focus on aspects that are most relevant in the present context. In this case both dispersive and nonlinear effects are active during the formation of the waves, and the value of $\tau$ is somewhat dependent on the time at which the wavelength is measured. After $500 \mathrm{~s}$ the generation is virtually finished and we find $\lambda=36 \mathrm{~km}$ at a depth of $4 \mathrm{~km}$. For a propagation distance of $500 \mathrm{~km}$ this leads to a value of $\tau$ close to unity. After crossing the Atlantic Ocean we find $\tau \sim 10$. The resolution in the transoceanic simulations is $2^{\prime}$, while much finer grids were employed in more local simulations around the Canary Islands.

Some results are shown in Fig. 14. We observe a strong directivity and that the leading crest is not dominant in the time series shown. More surprisingly, in view of the large value of $\tau$, in the simulated time series for buoy 2 the deviation between the LSW solution and the dispersive solution is only moderate. It must then be remarked that the generation and early propagation are computed by a dispersive and nonlinear model up to $t=900 \mathrm{~s}$; then the solution is conveyed into either a linear dispersive model or a LSW model. At $t=900 \mathrm{~s}$ the leading crest is already stretched a lot by dispersive effects, and the subsequent evolution may thus be slower (see discussion below Eq. 8).

In Fig. 15 we show the evolution of the second incident crest as it enters the continental shelf of North America. An undular bore rapidly evolves and the front of the crest is split into a sequence of solitary waves. The heights of the individual peaks are close to the stability limit for solitary waves, and they will soon break during the following shoaling. At this location the first incident crest displays the highest surface elevation (not shown), but the second crest has higher 


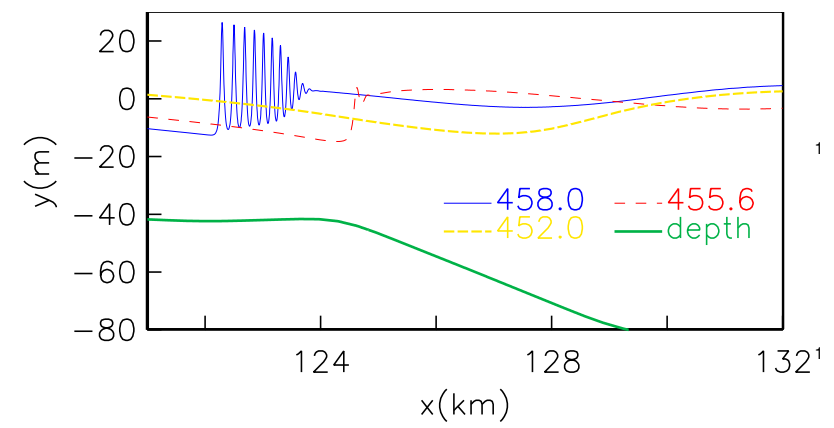

Fig. 15. Evolution of an undular bore from the second crest on the continental shelf of North Carolina. Waves propagate to the left. $y$ is the surface elevation $(\eta), x$ is the distance and the numbers in the legends correspond to the propagation time in minutes.

effective wave height due to the intermediate trough. Hence, the leading crest undergoes the transformation to an undular bore later, when it is closer to the coast. To resolve the undular bore properly, grid increments comparable to the depth, or preferably smaller, must be employed. Covering the continental shelf with a resolution of, say, $20 \mathrm{~m}$ will be a computational challenge. Moreover, when the crests start to break we still need a Boussinesq type model with breaking features implemented (see Korycansky and Lynett, 2005).

\subsection{Potential rockslides in Norwegian fjords, example from Åkerneset}

A large unstable rock volume has been identified in the Åkerneset rock slope in the narrow fjord, Storfjorden, Møre \& Romsdal County, Western Norway, Fig. 16. The site has been subject to extensive geological investigations (Blikra, 2008, 2012) and the tsunami has been studied experimentally and numerically (NGI, 2010; Harbitz et al., 2012b). We here focus on a comparison between the LSW and the dispersive solutions for a volume of $54 \times 10^{6} \mathrm{~m}^{3}$ and an impact velocity of $45 \mathrm{~m} \mathrm{~s}^{-1}$. In Fig. 16 we present surfaces along two transects: one through the generation area and one close to the fjord head at Geiranger. The dispersion is crucial during the tsunami generation and the early phases of propagation - see mid-panel of Fig. 16. This is also confirmed through laboratory experiments in both 2-D (Sælevik et al., 2009) and 3-D (NGI, 2010). The leading peak for the southgoing waves differ significantly in height (more than a factor two), wavelength, and shape between the two solutions. Later, after 9 min the leading parts of the two solutions are only slightly different along the transects outside Geiranger (lower panel of Fig. 16). This is surprising in view of both the dispersion time $\tau \sim 0.4$ and the large differences in the early stages. Presumably geometrical effects, in particular the fjord bifurcation, may have selectively transmitted longer components into the branch leading to Geiranger (see Harbitz, 1992a; Nachbin and da Silva Simoes, 2012). This feature
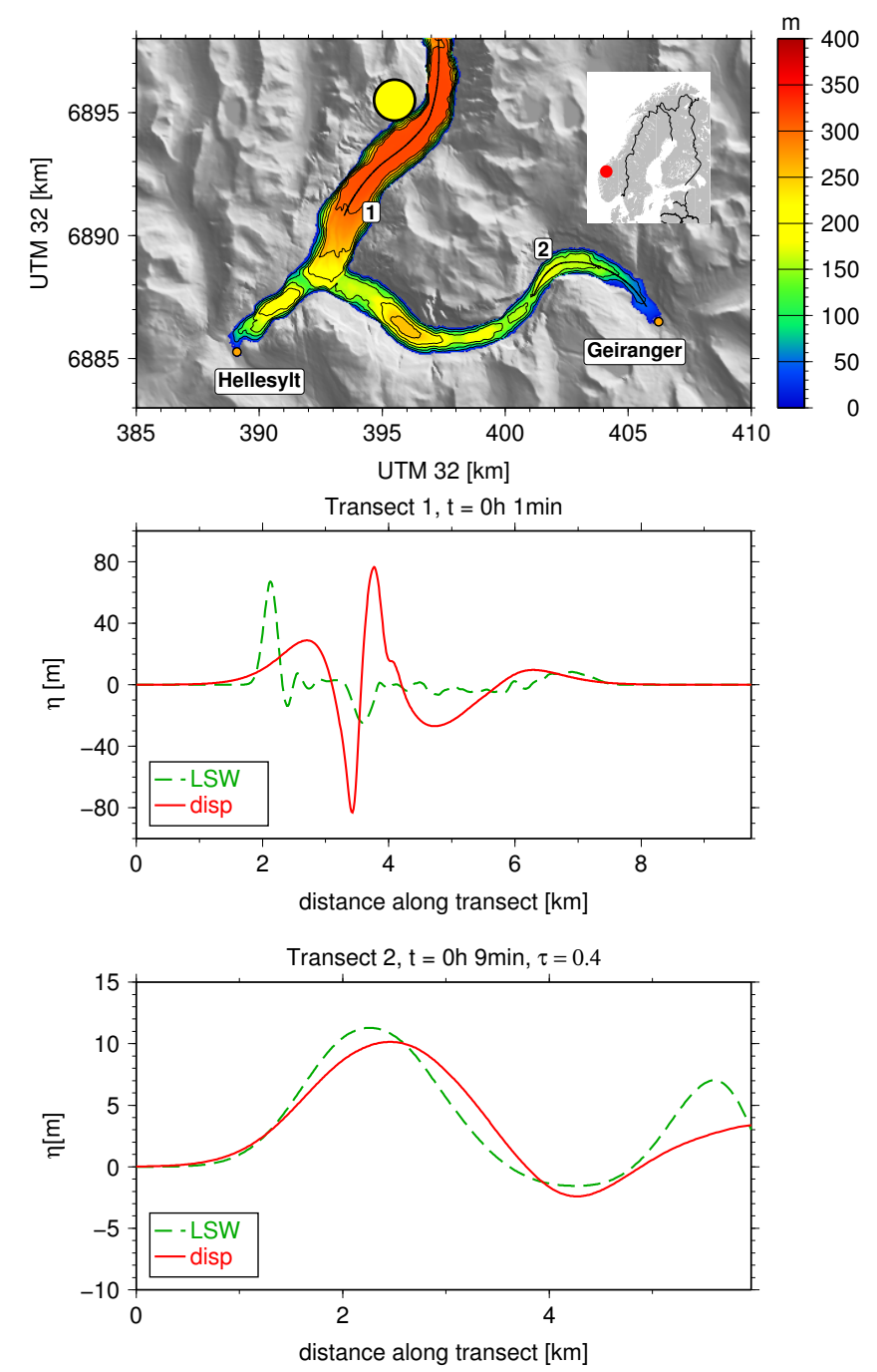

Fig. 16. Upper panel: Bathymetry of the inner part of the fjord system. Åkerneset is marked with a large yellow bullet. The numerical solutions are evaluated along the two transects, 1 and 2. The depth is given in meters. Mid-panel: LSW and linear dispersive solutions at the generation area (transect 1 , surface elevation). The leftmost waves are propagating to the left (south) and the rightmost waves are propagating to the right (north). The center line of the slide motion is found at about $3.5 \mathrm{~km}$. Lower panel: solutions along transect 2 outside Geiranger (surface elevation).

awaits further analysis, but may anyhow indicate that the dispersion time must be used with care in complex situations. The grid resolution in the computations was $50 \mathrm{~m}$.

\section{Conclusions}

In the cases investigated the value of the normalized dispersion time, $\tau$, is seen to correspond reasonably well with the apparent dispersive effects. As a rule of thumb we may say the effect of dispersion is small for $\tau<0.01$, while it 
generally becomes significant for $\tau>0.1$, say. The form of $\tau$ indicates that the source width/initial wavelength (for landslides) is more important for the significance of dispersion than the depth or propagation distance. Accordingly, we find that moderate-magnitude earthquakes yield more dispersive tsunamis than the huge ones, such as the 2004 Indian Ocean and the 2011 Japan tsunami.

For the largest earthquakes, frequency dispersion only modify the the transoceanic propagation mildly. Hence, dispersion is not needed for propagation in the near-field, but may be important if far-field tsunami data are used for verification of source properties.

For the smaller earthquakes ( $M_{\mathrm{w}} \sim 8$ or less) we observe a strong directivity of the dispersion, following the amplitude directivity, due to the elongated shapes of the source regions. In the offshore direction normal to the fault line, the tsunami signal must be expected to become completely transformed before reaching buoys or other continents.

On the other hand, most landslide-induced tsunamis are strongly affected by dispersive effects. For the leading part of the signal, such effects are generally most important during wave generation and the early stages of propagation, while the far-field properties may presumably be different for subaerial (net volume in tsunami) and submarine (no net volume) landslides. Extremely large landslides, moving at small Froude numbers, such as the Storegga Slide, are the likely exception. The oceanic propagation of such events are virtually nondispersive.

From the above discussion it is tempting to conclude that a reasonable hazard assessment in the near-field for tsunamis of seismic origin may be based on shallow-water theory, which is favorable with respect to real-time tsunami computations for warning purposes. However, undular bores, which are not included in shallow-water theory, may evolve during shoaling. Even though such bores may double the wave height locally, their effect on inundation is more uncertain because the individual crests are short and may be strongly affected by dissipation due to wave breaking.

Acknowledgements. This work has been supported by the Norwegian Research Council under project no. 205184. The University of Oslo (UiO), the Norwegian Geotechnical Institute (NGI), and the International Centre for Geohazards (ICG) are also thanked for supporting the work on this manuscript. This is contribution no. 421 of the ICG. The reviewers, Jörn Behrens and one anonymous referee, are thanked for their valuable comments on the manuscript.

Edited by: I. Didenkulova

Reviewed by: J. Behrens and one anonymous referee

\section{References}

Abadie, S. M., Harris, J. C., Grilli, S. T., and Fabre, R.: Numerical modeling of tsunami waves generated by the flank collapse of the Cumbre Vieja Volcano (La Palma, Canary Islands): Tsunami source and near field effects., J. Geophys. Res., 117, C05030, doi:10.1029/2011JC007646, 2012.

Arcas, D. and Segur, H.: Seismically generated tsunamis, Phil. Trans. R. Soc. A, 370, 1505-1542, doi:10.1098/rsta.2011.0457, 2012.

Bardet, J.-P., Synolakis, C. E., Davies, H. L., Imamura, F., and Okal, E. A.: Landslide Tsunamis: Recent Findings and Research Directions, Pure Appl. Geophys., 160, 1793-1809, 2003.

Bilham, R.: A Flying Start, Then a Slow Slip, Science, 308, 11261127, 2005.

Blaser, L., Krüger, F., Ohrnberger, M., and Scherbaum, F.: Scaling relations of earthquake source parameter estimates with special focus on subduction environment, Bull. Seismol. Soc. Am., 100, 2914-2926, 2010.

Blikra, L.: The Åknes rockslide; monitoring, threshold values and early-warning., in: Landslides and Engineered Slopes. From the Past to the Future. Proceedings of the 10th International Symposium on Landslides and Engineered Slopes, 30 June-4 July 2008, Xi' an, China, edited by: Chen, Z., Zhang, J.-M., Ho, K., Wu, F.Q., and Li, Z.-K., Taylor and Francis, ISBN: 978-0-415-41196-7, 2008.

Blikra, L. H.: The Åknes rockslide, Norway, in: Landslides: Types, Mechanisms and Modeling, edited by: Clauge, J. and Stead, D., Cambridge University Press, 323-335, 2012.

Bondevik, S., Svendsen, J., Johnsen, G., Mangerud, J., and Kaland, P.: The Storegga tsunami along the Norwegian coast, its age and runup, Boreas, 26, 29-53, 1997a.

Bondevik, S., Svendsen, J., and Mangerud, J.: Tsunami sedimentary facies deposited by the Storegga tsunami in shallow marine basins and coastal lakenews, western Norway, Sedimentology, 44, 1115-1131, 1997b.

Bondevik, S., Løvholt, F., Harbitz, C., Mangerud, J., Dawson, A., and Svendsen, J.: The Storegga slide tsunami comparing field observations with numerical simulations, Ormen Lange Special Issue, Mar. Petrol. Geol., 22, 195-208, 2005.

Bryn, P., Berg, K., Forsberg, C., Solheim, A., and Kvalstad, T.: Explaining the Storegga slide, Mar. Petrol. Geol., 22, 11-19, doi:10.1016/j.marpetgeo.2004.12.003, 2005.

Bugge, T., Befring, S., Belderson, R., Eidvin, T., Jansen, E., Kenyon, N., and Sejrup, H. H. H.: A giant three-stage submarine slide off Norway, Geo-Mar. Lett., 7, 191-198, doi:10.1007/BF02242771, 1987.

Bugge, T., Belderson, R., and Kenyon, N.: The Storegga slide, Trans. R. Soc., 325, 357-388, 1988.

Clarisse, J.-M., Newman, J. N., and Ursell, F.: Integrals with a large parameter: water waves on finite depth due to an impulse, Proc. Roy. Soc. Ser. A, 450, 67-87, 1995.

Dawson, A., Long, D., and Smith, D.: The Storegga Slides: Evidence from eastern Scotland for possible tsunami, Mar. Geol., 82, 271-276, 1988.

Dengler, L. and Preuss, J.: Mitigation Lessons from the July 17, 1998: Papua New Guinea Tsunami, Pure Appl. Geophys., 130, 2001-2033, 2003.

Dorn, W. G. V., Méhaute, B. L., and Hwang, L.-S.: Handbook of explosion-generated water waves, 1968. 
Dutykh, D., Dias, F., and Kervella, Y.: Linear theory of wave generation by a moving bottom, C.R. Acad. Sci. Paris, Ser. I, 343, 499-504, 2006.

Geist, E.: Source characteristics of the July 17, 1998, Papua New Guinea Tsunami, Abstract EOS, Transactions AGU, Fall Meeting, 571-572, 1998a.

Geist, E.: Local tsunamis and earthquake source parameters, Adv. Geophys., 39, 117-209, 1998b.

Gisler, G., Weaver, R., and Gittings, M. L.: SAGE calculations of the tsunami threat from La Palma, Sci. Tsunami Hazards, 24, 288-301, 2006.

Gjevik, B., Pedersen, G., Dybesland, E., Harbitz, C. B. C., Miranda, P. M. A., Baptista, M. A., Mendes-Victor, L., Heinrich, P., Roche, R., and Guesmia, M.: Modeling tsunamis from earthquake sources near Gorringe Bank southwest of Portugal, J. Geophys. Res., 102, 927-949, 1997.

Glimsdal, S., Pedersen, G., Atakan, K., Harbitz, C. B., Langtangen, H. P., and Løvholt, F.: Propagation of the Dec. 26, 2004 Indian Ocean Tsunami: effects of dispersion and source characteristics, Int. J. Fluid Mech. Res., 33, 15-43, 2006.

Glimsdal, S., L’Heureux, J.-S., Harbitz, C. B., and Pedersen, G. K.: Modelling of the 1888 landslide tsunami, Trondheim, Norway, in: Proceedings of the Second World Landslide Forum, 3-7 October, 2011.

Grilli, S. and Watts, P.: Tsunami generation by submarine mass failure Part I: Modeling, experimental validation, and sensitivity analysis., J. Waterway Port Coast. Ocean Eng., 131, 283-297, 2005.

Grilli, S., Harris, J., Tajalibakhsh, T., Kirby, J., Shi, F., Masterlark, T., and Kyriakopoulos, C.: Numerical simulation of the 2011 Tohoku tsunami: Comparison with field observations and sensitivity to model parameters, in: Proc. 22nd Offshore and Polar Engng. Conf. (ISOPE12, Rodos, Greece, 17-22 June 2012), Intl. Society of Offshore and Polar Eng., 2012.

Grue, J., Pelinovsky, E. N., Fructus, D., Talipova, T., and Kharif, C.: Formation of undular bores and solitary waves in the Strait of Malacca caused by the 26 December 2004 Indian Ocean tsunami, J. Geophys. Res., 113, C05008, doi:10.1029/2007JC004343, 2008.

Haflidason, H., Sejrup, H., Nygard, A., Meinert, J., Bryn, P., Lien, R., Forsberg, C., Berg, K., and Masson, D.: The Storegga slide: architecture, geometry and slide development, Mar. Geol., 213, 201-234, doi:10.1016/j.margeo.2004.10.007, 2004.

Harbitz, C.: Reflection-transmission of nonlinear waves in channel bends, Tech. Rep. 6, Institute of Mathematics, University of Oslo, Norway, preprint series, ISBN 82-553-0775-3, 1992a.

Harbitz, C., Glimsdal, S., Bazin, S., Zamora, N., Løvholt, F., Bungum, H., Smebye, H., Gauer, P., and Kjekstad, O.: Tsunami hazard in the Caribbean: Regional exposure derived from credible worst case scenarios, Cont. Shelf Res., 38, 1-23, 2012a.

Harbitz, C., Glimsdal, S., Løvholt, F., Pedersen, G., Jensen, A., and Kveldsvik, V.: Rock slide tsunamis in complex fjords: From an unstable rock slope at Åkerneset to tsunami risk in western Norway, Coastal Eng., under review, 2012 b.

Harbitz, C. B.: Model simulations of tsunamis generated by the Storegga Slides, Mar. Geol., 105, 1-21, 1992b.

Harbitz, C. B., Løvholt, F., Pedersen, G., Glimsdal, S., and Masson, D. G.: Mechanisms of tsunami generation by submarine gravity mass flows, Norwegian J. Geol., 86, 255-264, 2006.
Haugen, K., Løvholt, F., and Harbitz, C.: Fundamental mechanisms for tsunami generation by submarine mass flows in idealised geometries, Mar. Petrol. Geol., 22, 209-217, 2005.

Horrillo, J., Kowalik, Z., and Shigihara, N.: Wave dispersion study in the Indian Ocean Tsunami of December 26, 2004, Sci. Tsunami Hazards, 25, 42-63, 2006.

Hunt, J., Wynn, R. B., Masson, D. G., Tallin, P. J., and Teagle, D.: Sedimentological and geochemical evidence for multistage failure of volcanic island landslides: A case study from Icod landslide on north Tenerife, Canary Islands., Geochem. Geophys. Geosyst., 12, doi:10.1029/2011GC003740, 2011.

Ioualalen, M., Asavanant, J., Kaewbanjak, N., Grilli, S. T., Kirby, J. T., and Watts, P.: Modeling the 26 December 2004 Indian Ocean tsunami: Case study of impact in Thailand, J. Geophys. Res., 112, C07024, doi:10.1029/2006JC003850, 2007.

Kajiura, K.: The leading wave of a tsunami, Bull. Earthq. Res. Inst., 41, 535-571, 1963.

Kennedy, A. B., Chen, Q., Kirby, J. T., and Dalrymple, R. A.: Boussinesq modeling of wave transformation, breaking, and runup, Part I: 1D, J. Waterw. Port, Coast. Ocean Eng., 126, 39-47, 2000.

Kervella, Y., Dutykh, D., and Dias, F.: Comparison between three-dimensional linear and nonlinear tsunami generation models, Theor. Comput. Fluid Dynam., 21, 245-269, doi:10.1007/s00162-007-0047-0, 2007.

Kim, D.-H. and Lynett, P.: Turbulent mixing and passive scalar transport in shallow flows, Phys. Fluids, 23, 016603, doi:10.1063/1.3531716, 2011.

Kirby, J., Shi, F., Tehranirad, B., Harris, J., and Grilli, S. T.: Dispersive tsunami waves in the ocean: Model equations and sensitivity to dispersion and Coriolis effects, Ocean Model., 62, 39-55, 2013.

Korycansky, D. G. and Lynett, P. J.: Offshore breaking of impact tsunami: The Van Dorn effect revisited, Geophys. Res. Lett., 32, L10608, doi:10.1029/2004GL021918, 2005.

Kvalstad, T., Andresen, L., Forsberg, C., Bryn, K. B., and Wangen, M.: The Storegga slide: evaluation of triggering sources and slide mechanics, Mar. Petrol. Geol., 22, 245-256, doi:10.1016/j.marpetgeo.2004.10.019, 2005.

Lay, T., Ammon, C., Kanamori, H., Xue, L., and Kim, M.: Possible large near-trench slip during the $2011 \mathrm{Mw} 9.0$ off the Pacific coast of Tohoku Earthquake, Earth Planet. Space, 63, 687-692, 2011.

Leonard, M.: Earthquake fault scaling: Self-consistent relating of rupture length, width, average displacement, and moment release, Bull. Seismol. Soc. Am., 100, 1971-1988, 2010.

Løvholt, F., Pedersen, G., and Gisler, G.: Oceanic propagation of a potential tsunami from the La Palma Island, J. Geophys. Res., 113, C09026, doi:10.1029/2007JC004603, 2008.

Løvholt, F., Pedersen, G., and Glimsdal, S.: Coupling of dispersive tsunami propagation and shallow water coastal response, Open Oceanography J., 4, 71-82, 2010.

Løvholt, F., Glimsdal, S., Harbitz, C., Zamora, N., Nadim, F., Pedduzzi, P., Dao, H., and Smebye, H.: Tsunami hazard and exposure on the global scale, Earth-Sci. Rev., 110, 58-73, 2012a.

Løvholt, F., Kaiser, G., Glimsdal, S., Scheele, L., Harbitz, C. B., and Pedersen, G.: Modeling propagation and inundation of the 11 March 2011 Tohoku tsunami, Nat. Hazards Earth Syst. Sci., 12, 1017-1028, doi:10.5194/nhess-12-1017-2012, 2012b. 
Løvholt, F., Pedersen, G., S. Bazin, D. K., Bredesen, R. E., and Harbitz, C.: Stochastic analysis of tsunami run-up due to heterogeneous co-seismic slip and dispersion, J. Geophys. Res., 117, C03047, doi:10.1029/2011JC007616, 2012.

Lynett, P. J., Wu, T.-R., and Liu, P. L.-F.: Modeling wave runup with depth-integrated equations, Coast. Eng., 46, 89-107, 2002.

Lynett, P. J., Borrero, J. C., Liu, P. L.-F., and Synolakis, C. E.: Field survey and Numerical Simulations: A review of the 1998 Papua New Guinea Tsunami, Pure Appl. Geophys, 160, 2119-2146, 2003.

Mader, C.: Modelling the La Palma landslide tsunami, Sci.Tsunami Hazards, 19, 150-170, 2001.

Madsen, P. and Sørensen, O.: A new form of the Boussinesq equations with improved linear dispersion characteristics, Part 2. A slowly-varying bathymetry, Coast. Eng., 18, 183-204, 1992.

Madsen, P. A., Fuhrman, D. R., and Schäffer, H. A.: On the solitary wave paradigm for tsunamis, J. Geophys. Res., 113, C12012, doi:10.1029/2008JC004932, 2008.

Mai, P. M. and Beroza, G. C.: A spatial random field model to characterize complexity in earthquake slip, J. Geophys. Res., 107, 2308, doi:10.1029/2001JB000588, 2002.

Masson, D. G., Watts, A., Gee, M., Urgeles, R., Mitchell, N., Bas, T. L., and Canals, M.: Slope failures on the flanks of the western Canary Islands, Earth-Sci. Rev., 57, 1-35, 2002.

Masson, D. G., Harbitz, C., Wynn, R. B., Pedersen, G., and Løvholt, F.: Submarine Landslides -processes, triggers and hazard prediction, Phil. Trans. Roy. Soc., A364, 2009-2039, 2006.

McSaveney, M., Goff, J., Darby, D., Goldsmith, P., Barnett, A., Elliott, S., and Nongkas, M.: The 17 July 1998 tsunami, Papua New Guinea: evidence and initial interpretation, Mar. Geol., 170, 8192, 2000.

Mei, C. C.: The Applied Dynamics of Ocean Surface Waves, World Scientific, 1989.

Mesinger, F. and Arakawa, A.: Numerical methods used in atmospheric models, GARP, Publ. Ser. WMO, 17, 1-64, 1976.

Nachbin, A. and da Silva Simoes, V.: Solitary waves in open channels with abrupt turns and branching points, J. Nonlinear Math. Phys., 19, doi:10.1142/S1402925112400116, 2012.

NGI: Åknes/Tafjord-project: Numerical simulations of tsunamis from potential and historical rock slides in Storfjorden; Hazard zoning and comparison with 3D laboratory experiments, report 20051018-00-1-R, Norwegian Geotechnical Institute, 2010.

Nwogu, O.: Alternative Form of Boussinesq Equations for Nearshore Wave Propagation, J. Waterw. Port Coast. Ocean Eng., 119, 618-638, 1993.

Okada, Y.: Surface deformation due to shear and tensile faults in a half-space., Bull. Seism. Soc. Am., 75, 1135-1154, 1985.

Okal, E. A. and Synolakis, C. E.: Source discriminants for near-field tsunamis, Geophys. J. Int., 158, 899-912, 2004.

Ozawa, S., Nishimura, T., Suito, H., Kobayashi, T., Tobita, M., and Imakiire, T.: Coseismic and postseismic slip of the 2011 magnitude-9 Tohohu-Oki earthquake, Nature, 475, 373-376, doi:10.1038/nature10227, 2011.

Pedersen, G.: A note on tsunami generation by earthquakes, Preprint Series in Applied Mathematics 4, Dept. of Mathematics, University of Oslo, Norway, available at: http://urn.nb.no/URN: NBN:no-27814 (last access: 16 May 2013), 2001.

Pedersen, G. and Løvholt, F.: Documentation of a global Boussinesq solver, Preprint Series in Applied Mathematics 1, Dept. of
Mathematics, University of Oslo, Norway, available at: http: //urn.nb.no/URN:NBN:no-27775 (last access: 16 May 2013), 2008.

Peregrine, D. H.: Long waves on a beach, J. Fluid Mech., 77, 417431, 1967.

Pophet, N., Kaewbanjak, N., Asavanant, J., and Ioualalen, M.: High grid resolution and parallelized tsunami simulation with fully nonlinear Boussinesq equations, Comput. Fluids, 40, 258-268, 2011.

Sælevik, G., Jensen, A., and Pedersen, G.: Experimental investigation of impact generated tsunami; related to a potential rock slide, Western Norway, Coastal Eng., 56, 897-906, 2009.

Shi, F., Kirby, J., Harris, J., Geiman, J., and Grilli, S.: A high-order adaptive time-stepping TVD solver for Boussinesq modeling of breaking waves and coastal inundation, Ocean Model., 43-44, 31-51, 2012.

Shuto, N.: The Nihonkai-Chubu Earthquake Tsunami on the North Akita Coast, Coastal Eng. Jpn., 28, 255-264, 1985.

Shuto, N.: Numerical simulation of tsunamis - Its present and near future, Nat. Hazards, 4, 171-191, 1991.

Sitanggang, K. I. and Lynett, P.: Parallel computation of a highly nonlinear Boussinesq equation model through domain decomposition, Int. J. Numer. Meth. Fluids, 49, 57-74, 2005.

Stein, S. and Okal, E. A.: Speed and size of the Sumatra earthquake, Nature, 434, 581-582, 2005.

Stiassnie, M.: Tsunamis and acoustic-gravity waves from underwater earthquakes, J. Eng. Math., 67, 23-32, 2010.

Sweet, S. and Silver, E.: Tectonics and slumping in the source region of the 1998 Papua New Guinea tsunami from seismic reflection images, Pure Appl. Geophys., 160, 1945-1968, 2003.

Synolakis, C., Bardet, J.-P., Borrero, J., Davies, H., Okal, E., Silver, E., Sweet, S., and Tappin, D.: The slump origin of the 1998 Paua New Guinea Tsunami, The Royal Society, 457, 1-27, 2001.

Tappin, D., Watts, P., and Matsumoto, T.: Architecture and failure mechanism of the offshore slump, in: Submarine Mass Movements and Their Consequences, edited by: Locat, J. and Mienert, J., Kluver Academic Publishers, 383-389, 2003.

Tappin, D. R., Watts, P., and Grilli, S. T.: The Papua New Guinea tsunami of 17 July 1998: anatomy of a catastrophic event, Nat. Hazards Earth Syst. Sci., 8, 243-266, doi:10.5194/nhess-8-2432008, 2008.

Ursell, F.: The long-wave paradox in the theory of gravity waves, Math. Proc. Cambridge Phil. Soc., 49, 685-694, doi:10.1017/S0305004100028887, 1953.

Vanneste, M., Harbitz, C., Blasio, F. D., Glimsdal, S., Mienert, J., and Elverhøi, A.: Hinlopen-Yermak Landslide, Arctic Ocean Geomorphology, landslide dynamics and tsunami simulations, in: Mass-Transport Deposits in Deepwater Settings, edited by: Shipp, R., Weimer, P., and Posamentier, H., vol. 96, Society for Sedimentary Geology, Special Publication, 2011.

Ward, S. N.: Landslide tsunami, J. Geophys. Res., 6, 11201-11215, 2001.

Ward, S. N. and Day, S.: Cumbre Vieja Volcano-potential collapse and tsunami at La Palma, Canary Islands, Geophys. Res. Lett., 28, 397-400, 2001.

Whitham, G. B.: Linear and nonlinear waves, Pure \& Applied Mathematics, John Wiley \& sons, 1974.

Wynn, R. B. and Masson, D. G.: Canary Island landslides and tsunami generation: can we use turbidite deposits to interpret 
lansdlide processes?, in: Submarine Mass Movements and their Consequence, edited by: Locat, J. and Mienert, J., Kluwer Academic Publishers, Dordrecht, Boston, London, 2003.

Zhou, H., Moore, C. W., Wei, Y., and Titov, V. V.: A nestedgrid Boussinesq-type approach to modelling dispersive propagation and runup of landslide-generated tsunamis, Nat. Hazards Earth Syst. Sci., 11, 2677-2697, doi:10.5194/nhess-11-26772011, 2011.
Zhou, H., Wei, Y., and Titov, V. V.: Dispersive modeling of the 2009 Samoa tsunami, Geophys. Res. Lett., 39, L16603, doi:10.1029/2012GL053068, 2012. 